\title{
ESTUDIOS
}

\section{Fundamentos filosóficos de una pedagogía personalista}

\section{Tura Pedemonte Feu'}

Resumen: El ensayo presenta sucesivamente algunas interpelaciones y contribuciones esenciales del pensamiento filosófico europeo del siglo XX que solemos agrupar como personalismo, aunque se recojan otras aportaciones, y busca a partir de ellas la fundamentación de una acción educativa de inspiración personalista. El autor trata especialmente de Paul Ricoeur y de algunos otros pensadores de tradición judía (Espinosa, Rosenzweig, Arendt, Buber, Lévinas). Después de desarrollar las cinco notas que estima más destacables: identidad, narratividad, acción, alteridad y transcendencia, el ensayo concluye con una invitación a la escuela de inspiración personalista para hacer manifiestos sus presupuestos, concretamente la invitación a la transcendencia desde un respeto profundo por la persona del otro, hasta encontrar el punto justo, aunque difícil, en que la propuesta de lo transcendente, deba concretarse en cada situación que señalará el momento y la forma oportuna de hacerla posible.

Palabras clave: acción, alteridad, educación, identidad, narratividad, personalismo, transcendencia.

Fecha de recepción: 3 de julio de 2017.

Fecha de admisión definitiva: II de julio de 2017.

\section{Philosophical bases of personalist pedadogy}

Abstract: This essay successively presents some essential questions and contributions of the European philosophical thought in
Les fondements philosophiques d'une pédagogie personnaliste

Résumé: L'essai présente successivement quelques interpellations et contributions

' Centre Saint Augustin, Dakar (Senegal) e Instituto Emmanuel Mounier (Grupo de reflexión personalista Emmanuel Mounier). Doctor en Filosofía, Institut Catholique de Paris (ICP), París. 
the 20th century that are usually grouped as personalism and, while it contains other contributions, building on them, this paper seeks to inform a personalist-based educational strategy. The author deals especially with Paul Ricoeur and with some other thinkers of Jewish tradition (Espinosa, Rosenzweig, Arendt, Buber, Lévinas). The author elaborates the five aspects which he considers most remarkable (identity, narrativity, action, alterity and transcendence) and, then, the essay concludes with an invitation to the personalist school of thought to express its presuppositions. In particular, it offers an invitation to transcendence with a deep respect for others, to the point, although difficult, where the proposal of transcendence is made concrete in each specific situation that will point the time and the correct manner to make it possible.

Keywords: Action, otherness, education, identity, narrative, personalism, trascendence. essentielles de la pensée philosophique européenne du XXe siècle que nous avons I'habitude de grouper comme personnalisme, même si d'autres contributions sont aussi recueillies, tout cherchant en elles la base $d$ 'une action éducative $d$ 'inspiration personnaliste. L'auteur agit particulièrement de Paul Ricoeur et d'autres penseurs de tradition juive (Espinosa, Rosenzweig, Arendt, Buber, Levinas). Après avoir développé les cinq notes qu'il juge les plus remarquables: I'identité, la narrativité, l'action, l'altérité et la transcendance, l'essai se finie par une invitation à l'école d'inspiration personnaliste de manifester leur présomptions, en particulier l'invitation à la transcendance depuis un profond respect pour la personne à l'autre, jusqu'à retrouver le vrai point, quoique il soit difficile, où la proposition du transcendant, devrait se matérialiser à chaque situation qui précisera le moment et la forme qui soient opportunes pour le rendre possible.

Mots clé: action, altérité, éducation, identité, narrativité, personnalisme, transcendance.

\section{Introducción}

Esta reflexión no pasaría de ser una abstracción si no tuviera en cuenta el contexto en que está situada, es decir que hay que verla dentro de un horizonte marcado por unas condiciones de espacio y de tiempo. Se configura dentro de nuestro mundo occidental en el primer cuarto del siglo XXI, marcado por el dominio de un neocapitalismo feroz. El sistema en que estamos inmersos no tiene consideración ninguna por los valores de la persona, hasta el extremo que el ser humano es conducido al umbral de un individualismo perverso que lo halaga con todas las ventajas de un mundo donde se vive bien y, a la vez, lo utiliza y lo explota por vías indecorosas y desprovistas de respeto. Vivimos inmersos en un mundo agresivo y cada vez más indiferente al sufrimiento de los demás, pero lo que considero más grave es que esta situación se llegue a justificar a través de un pensamiento llamado débil porque ha perdido la fuerza y la consistencia de una razón crítica 
y ha renunciado a la búsqueda de un fundamento metafísico. Entonces todo se convierte en líquido e inconsistente, el hombre, la sociedad y la verdad. Los valores no valen y nada progresa hacia una plenitud, de manera que no hay nada que esperar ni del hombre ni del mundo ni de Dios. Estas actitudes se muestran también en el carácter selectivo de nuestros planes educativos que no están pensados para construir la dignidad del hombre y la mujer, sino que buscan integrar a algunos alumnos al tren victorioso de los éxitos efímeros, y abandonan a la mayoría a les escurriduras de una existencia marginal. Buscan crear unos modelos estándar según las demandas del mercado de trabajo que están movidas por los intereses del capital. Puro utilitarismo que desprecia la prioridad del valor de la persona. Por este motivo vemos que las materias que puedan tener una incidencia que humaniza o crítica son arrinconadas en beneficio de las que tienen un contenido técnico².

Quisiera concretar esta crítica general en tres aspectos que son para mí particularmente negativos y que son tres obstáculos para caminar en la dirección de una educación personalizadora. Son el escepticismo-nihilismo, el pragmatismo y el universalismo oceánico que nos propone el ambiente social en que nos movemos.

En primer lugar el escepticismo y el nihilismo que empañan nuestras posibilidades de conocer la verdad o nuestra afirmación del ser, como afirmación de algo consistente. Los dos planteamientos se mueven en terrenos diferentes, pero a menudo coinciden como las dos caras de una moneda. El primero está formulado en el terreno gnoseológico: ¿ $\mathrm{H}$ hay verdad en nuestro conocimiento? Y el escéptico responde: no. El segundo está formulado en el campo ontológico: ¿Qué hay? Y el nihilista responde: no hay nada. Evidentemente, ambas actitudes se han vestido históricamente de maneras distintas. El escepticismo es tan antiguo como la Filosofía y aparece siempre como un fármaco benéfico para oponerse a las manifestaciones dogmáticas o excesivas. Apareció con los sofistas para superar la polémica entre los filósofos de la consistencia y los del cambio; volvió a manifestarse en el umbral de la modernidad cuando caían los principios del geocentrismo y aparecía la ciencia nueva. Montaigne preconizó el escepticismo como una actitud sanadora, y todavía Hume se mostró partidario de mantener solamente un "belief" como posibilidad de hacer frente a una melancolía mortal. Hoy vuelve con un matiz más burdo y menos optimista, con el tono de quien está de vuelta y propone conceptos que impiden avanzar, ya que van precedidos por el prefijo post. Habíamos hablado de postmodernidad y ahora hablamos de posthumanismo y posverdad.

2 El presente texto reproduce parte de una versión previa aparecida en catalán y contiene otra parte inédita. La traducción al castellano es del autor. Una versión más amplia será publicada en su momento por el Instituto Emmanuel Mounier de Madrid, en cuyo contexto se ha realizado la presente investigación. 
El escéptico antiguo no había negado el concepto, sino el contenido. Su actitud de decir "no hay verdad" es muy distinta de la actitud de quien dice "la verdad no es nada". Aquí, la derrota de nuestro conocimiento llega a ser todavía mayor. Todo vale porque nada vale.

Lo que es negativo en el campo gnoseológico se traduce también en una negatividad en el terreno ontológico. Ante el problema del ser el nihilista responde: no hay nada, ni ser ni valores ni consistencia, ya que en la sociedad líquida en que nos encontramos inmersos nada vale nada. En este nihilismo que se manifiesta como una crisis de valores, no es posible orientarse porque no hay referentes, no hay modelos. En el fondo no hay metafísica. Pero sin referentes, sin modelos y sin metafísica, el hombre tampoco vale nada ni la educación tiene sentido alguno, porque no hay dirección a tomar ni hay a dónde ir. Un cierto ambiente de tododa-lo-mismo y la falta de aspiraciones dejan totalmente desorientados a los jóvenes cuando se abren a la vida. Se encuentran en una situación que los hace incapaces de decidir, simplemente porque nunca lo han hecho, nunca en su vida han tenido una confrontación seria, pero cuando tienen que decidir por primera vez están faltos de referentes. El reto educativo es serio porque en él se trata de recuperar los valores, el ser, la consistencia, para construir una propuesta educativa capaz de hacer crecer la persona.

Una segunda actitud que presenta nuestra época y que considero también negativa para una educación seria de la persona es el pragmatismo, según el cual el valor de las cosas depende de los resultados. Habría que proponer antes que nada una distinción entre la doctrina pragmatista que hemos citado y el método pragmatista que preconiza la práctica como camino de descubrimiento. No hace falta decir que el uso de un cierto pragmatismo consolida los aprendizajes desde el punto de vista que la práctica precede normalmente al saber. Para que nuestra crítica no resulte injustificada, conviene que se dirija, pues, a la afirmación teórica del pragmatismo, que asegura que la verdad en sí misma depende de la práctica: un enunciado teórico será verdad si es eficaz, si funciona. Según esta convicción todas las grandes ideas se verifican en la práctica. Nada es bueno o mal en sí mismo, si antes no se ha manifestado como conveniente o inconveniente para una acción determinada. En consecuencia, la valoración de las cosas se ajusta más bien a su carácter de utilidad. Este carácter utilitario reduce también el sujeto humano a un ser interesado que busca únicamente lo que le conviene. De esta manera la realidad sólo se verifica y recibe su valor en función de los intereses humanos. Hay que tener presente que, al lado de un pragmatismo de carácter individual y egocéntrico se manifestó también un pragmatismo de carácter más social, que guiaba su criterio buscando lo que es conveniente a la sociedad de manera que 
no apareciera tanto el carácter egoísta del individuo. Sin embargo, también en este caso la verificación final de los enunciados queda sometida a su eficacia. En realidad, constato que nuestra sociedad y nuestros ambientes están muy marcados por esos criterios de eficacia: hay que ser productivos, hay que ser personas de provecho, tenemos que optar por la excelencia de nuestros rendimientos, hay que mejorar nuestros resultados. Nuestra educación es desgraciadamente tributaria de estos principios. Cuántos planes de estudios han quedado marcados por los presupuestos pragmatistas y la formación ha priorizado guiarse por los estándares de excelencia, a olvidar el bien de la persona para fomentar la productividad social, cuántas veces los planes educativos han sido orientados de una manera servil a obtener tal tipo o tal otro de servicios que las empresas necesitan.

El tercer aspecto es el universalismo oceánico. La humanidad actual se ha descubierto a sí misma viviendo en un mundo muy comunicado en el cual todos los colectivos humanos son cada vez más cercanos, las distancias se han acortado y el planeta se ha vuelto más pequeño. Toda la sociedad se encuentra involucrada en una situación nueva en la que los hombres y mujeres habitan en un único mundo globalizado. Un nuevo pensamiento ha ido surgiendo, movido por la extensión y por la rapidez de las comunicaciones y sacudido por la interrelación de los problemas. Este pensamiento converge hacia la idea de un hombre universal y globalizado. Se ha inspirado en muchos casos en el descubrimiento de las espiritualidades orientales, especialmente del budismo o del taoísmo, y ha sido influido por las técnicas de dominio del cuerpo y de la mente. Todo ello ha desembocado en una actitud de identificación espiritual con la totalidad de la naturaleza y en la disolución de lo que es personal. Este modelo espiritual podría ser llamado "oceanismo globalizador", por aquello de la gota de agua disuelta en el océano. Esta tercera actitud encuentra muchos adeptos entre los que huyen de nuestro mundo materialista buscando una respuesta espiritual. El espíritu se siente inmerso en aquel mar de totalidad en que se pierde. La búsqueda de una paz interior lleva también a la idea de que todos somos uno y que sólo conseguimos la unidad en la medida que nos vaciamos de nosotros mismos. El precio a pagar por aquella serenidad interior es la disolución de la propia persona, la pérdida de la propia iniciativa y, más aún, la renuncia a la propia responsabilidad. No creo que sea éste el camino que haga madurar la persona, y que la lleve a una vida más autónoma y responsable, sino que más bien parece una vía hacia la evasión de cualquier compromiso y una voluntad de olvidar cualquier responsabilidad.

La crisis generalizada que vive nuestro mundo es en el fondo una crisis de pensamiento fuerte. Como si las facilidades de la tecnología actual hubiesen adormecido nuestro espíritu que se ha vuelto demasiado perezoso para interrogarse 
en profundidad y llegar a las últimas consecuencias. Por eso yo postulo una seria fundamentación del acto educativo, considerado como la realización de un proyecto fundamental que crea en la persona como idea directiva. Tal proyecto tiene que encarar el trato con cada hombre y cada mujer, en su estado de niño o de joven que se acerca a nuestras escuelas. Un tal proyecto se ofrece también a las familias como una tarea a realizar juntos, estando de acuerdo en unas mismas convicciones; finalmente es un proyecto que quiere ser un servicio a la sociedad humana que quisiéramos convertir en verdadera comunidad. Así pues, la relación de la escuela con las familias no tendría que reducirse a una relación contractual en la que se ofrecen unos servicios a cambio de dinero; tendría que ser más bien el primer paso de una verdadera comunidad en acción que busca desembocar en una vida más humana. Sin duda cada joven guiará libremente el timón de su nave hacia rutas bien diversas y nunca marcadas anticipadamente, pero cuando lo hagan ejercerán un acto de plena autonomía en el que podrán reconocer la educación recibida. A las dificultades obvias de la vida, de la naturaleza y del sistema, ellos opondrán otra evidencia, la de su existencia personal.

\section{2. ¿Qué es el hombre? La identidad de la persona}

Cada hombre es un todo... El sistema de la filosofía no existe en ningún otro lugar más que en el hombre mismo ${ }^{3}$. Acercarse a la realidad del hombre no es el camino de una abstracción, sino la aproximación al hombre concreto. ¿ Cómo presentarlo mínimamente? ¿̇n yo, una conciencia, un sujeto, una persona? Todas las definiciones claudican porque el hombre existente es esencialmente indefinible. Su ser no puede ser capturado en una idea. Cuando nos dirigimos esta pregunta a nosotros mismos, tampoco obtenemos una respuesta satisfactoria. ¿̇Quién soy, yo? Nos miramos al espejo y tenemos la impresión de encontrarnos ante un extraño. Cuando hemos explorado algunas de nuestras capacidades nos hemos topado también con nuestros límites, pero eso tampoco aclara nuestra búsqueda. Aunque muchos filósofos de todas las épocas han intentado responder a esta pregunta sobre la identidad del hombre, sus respuestas sólo se han aproximado tímidamente a la realidad de un gran misterio. Mi existencia, mi ser, es un misterio que se desenvuelve y que voy reconociendo en el tiempo que lleva del nacimiento a la muerte. Detrás de mí muchas posibilidades han quedado ya cerradas, y delante de mí quedan todavía muchas oportunidades abiertas que me resultan desconocidas. Algunas se me ofrecerán sin que yo las haya previsto o buscado, otras serán el objeto de

\footnotetext{
${ }^{3}$ ROSENZWEIG, F. Briefe 713. Carta a Rosenstock.
} 
mi querer o la frustración de mi fallo. Algunas me encontrarán preparado, otras se presentarán de improviso. Ante estos enigmas que he vivido y los demás que me esperan veo al hombre como un dinamismo capacitado para hacer muchas cosas en el mundo en que se encuentra situado y con la existencia que le ha sido ofrecida. Maine de Biran decía que el pensamiento y la personalidad del hombre eran el fruto de un esfuerzo y de su repetición, un esfuerzo que topa con las resistencias externas. Es como si el hombre estuviera situado entre dos extremos que lo solicitan cada uno hacia su posición, el extremo de lo finito y el extremo de lo infinito. La realidad que le toca vivir es, pues, una realidad desproporcionada, mediación entre dos extremos que Maine de Biran traducía en el principio: "homo duplex in humanitate sed simplex in vitalitate". Tal realidad de un "Homo capax" es la que Ricœur intenta describir a lo largo de su filosofía cuando emprende el camino de una reflexión de largo recorrido para explorar las posibilidades de la identidad de la persona. Mostrará esta capacidad humana de poder decir, poder obrar, poder narrar y narrarse $y$, finalmente, de poder considerarse imputable de las consecuencias de las acciones propias. Esta larga reflexión está expuesta en su obra más importante, "Soi-même comme un autre". En definitiva, nuestra aproximación a la identidad humana seguirá de cerca la reflexión de Ricœur que culminará en la presentación de un sujeto narrativo, es decir, un sujeto que se manifiesta a través de su historia, a la manera de una narración que se abre a la inteligencia lectora que quiera comprenderla. La investigación sobre la identidad del hombre puede comenzar por establecer dos cuestiones bastante triviales pero que pueden servir para situarnos. En efecto, podemos preguntarnos dónde estamos y hacia dónde nos dirigimos En el fondo, todos los trazos que describen nuestra identidad podrían reducirse a la respuesta a aquellas dos cuestiones, ya que el hombre tiene capacidad de dar razón de su situación y de su progreso.

Estas dos preguntas nos han de conducir a realizar nuestro propósito, que no es otro que trazar unas pinceladas de lo que tendría que ser una educación personalista y establecer cuáles son los criterios en que se basa. La pregunta sobre el dónde es al mismo tiempo una pregunta geográfica e histórica, que nos inscribe en el espacio y el tiempo. Ello significa que no podemos pensar nuestra condición humana fuera de las coordenadas del espacio y del tiempo. En concreto, eso significa que somos ciudadanos de un determinado país, que en nuestro caso es Cataluña, y que habitamos en un tiempo determinado, que es el siglo XXI, heredero de todas las crisis-sociales, económicas, políticas y culturales- que ya empezaron en el siglo XX. En resumen, vivimos en nuestro enclavamiento europeo bajo el peso de una historia que ya nos ha constituido antes de nuestro nacimiento. La vida de cada uno de nosotros ha aparecido dentro de este horizonte de referencia, que se particulariza todavía más con las cosas y los sucesos que han tejido la experien- 
cia viva de cada uno de nosotros y que se han ido conformando según nuestros propios intereses. De esta manera podemos describir nuestro mundo público en el cual nos encontramos situados. Este mundo se nos impone y no podemos negarlo a menos que intentemos huir de él escapándonos de la realidad. Es cierto que a la vida humana se le ofrecen escapatorias para huir de este mundo, que en muchos casos se vuelve amenazador. La actitud de quien rechaza el mundo o que se niega a reconocerlo se puede traducir en huidas fantasiosas, pasajeras o definitivas, que tarde o temprano conducen a la locura. En conclusión, podemos concluir que aquel horizonte de referencia que llamamos mundo nos impone una aceptación de base que no podemos cambiar.

Y sin embargo, aquel horizonte de nuestro vivir que constituye nuestro mundo ofrece una plasticidad con la que se puede interactuar en mayor o menor medida. Por un lado desde el horizonte el mundo estimula nuestros propios intereses, y por otro se ofrece también a nuestra transformación. Ricœur insinúa ya esta interacción en su obra primeriza, Le Volontaire et l'involontaire. No es solamente nuestro cuerpo, movido per el impulso de la necesidad, el que se encamina hacia aquello que ha de saciarlo, sino que desde fuera de él, desde la realidad del objeto conocido, recibe una llamada que le atrae

Aquí radica el hecho decisivo, cuando la necesidad ha descubierto su objeto y su itinerario no se tratará tan sólo de una falta o de un impulso que viene del cuerpo, sino de una llamada que viene de fuera de un objeto conocido. Yo no soy empujado fuera de mí únicamente desde mí mismo sino atraído fuera de mí a partir de alguna cosa que está en el mundo ${ }^{4}$

Podemos afirmar que el mundo es capaz de una transformación a través de nuestra propia acción, pero al mismo tiempo aquella transformación nos transforma también a nosotros mismos. La acción educativa se inscribe en esta transformación de lo que nos ha sido dado en nuestro entorno, que se traduce también en transformación de nosotros mismos. Por este motivo las dos cuestiones resultan pertinentes: dónde estamos y hacia dónde vamos. Hay que tener claro en qué mundo estamos y qué transformación pretendemos. Ello significa que hemos de tener claras las metas que nos hemos fijado para que puedan dirigir nuestro progreso.

La vida del hombre es un camino, un camino que no está trazado ciertamente, pero que hay que saber qué busca. Marcel describía al hombre como el homo viator, en el sentido de que su ser consiste en caminar $y$, en este sentido, estaba de acuerdo con las dos cuestiones que hemos propuesto, ya que no se puede caminar si no

${ }^{4}$ RICOEUR, P. (1986) Voluntario e involuntario, Buenos Aires, Docencia, p. 92. 
sabemos dónde nos encontramos ni hacia dónde vamos. Vivimos en una época de nihilismo y de crisis de valores y parece que en nuestros tiempos no esté bien visto hablar de "caminar». De hecho, algunas corrientes pedagógicas actuales se contentan con proponerse objetivos a corto plazo que pretenden satisfacer las necesidades inmediatas y responder a las pulsiones innatas, a la búsqueda de un hombre feliz. Algunos proyectos pedagógicos se limitan a buscar los medios tecnológicos que desarrollen aptitudes y capacidades sin preguntarse hacia dónde nos llevan. En realidad, el objetivo final del pedagogo, que ha de constituir el esqueleto del vivir humano, se ha pensado poco y, así, no disponemos de propuestas que se preocupen por una verdadera transformación del hombre. De hecho, una propuesta que sólo seduzca las pulsiones innatas de los individuos humanos con el afán de satisfacerlas, incluso si afirma perseguir como objetivo un mundo feliz, no sería una propuesta suficiente. El camino del hombre es más largo y más complejo que los objetivos que se proponen ciertas pedagogías. La realización del hombre no excluye el paso por la contrariedad y la experiencia de la propia debilidad, el error y el dolor se entrecruzan en el vivir humano y su progreso siempre está expuesto al fracaso. Eso quiere decir que el individuo humano tiene que asumir la contradicción si pretende llegar satisfactoriamente a sus metas. Pero una propuesta que redujera la acción educativa a una interacción mecánica de un mundo de robots, que estableciera la realidad de cada individuo como una prolongación a la respuesta de las máquinas, no podrí tampoco llenar las expectativas de la realización del hombre. Ya que por esta vía se colapsa la propia iniciativa, se esquiva el encuentro con la propia conciencia y se pierde la propia identidad. Es aquí donde un filósofo como Rosenzweig opone el individuo, es decir el hombre como formando parte de la naturaleza y de la sociedad o, dicho de otra forma, el hombre como objeto del sistema, al Yo, que se despierta al sentimiento de su realidad irreductible en la experiencia de su angustia ante la muerte, y que accede a su verdadera existencia personal en la experiencia de la Revelación. ${ }^{5}$

Llegados a este punto, hemos de avanzar nuestras convicciones, que se inscriben en una concepción, de la corriente personalista según la cual el hombre es persona. Nuestras ideas se encuentran focalizadas por el pensamiento de Mounier, por las corrientes de la filosofía de la conciencia y, sobre todo, por el seguimiento de unas directrices fenomenológicas que nos permitan avanzar sin extraer de ellas proposiciones dogmáticas de aspecto metafísico. Todo el hilo conductor es deudor del magisterio de Paul Ricœur, que me pasó la brújula para poder guiar felizmente el retorno de mi nave a ĺtaca.

${ }^{5}$ Moses, S. (1982) Système et Révélation. La philosophie de Franz Rosenzweig, París, Verdier, p. 45. 


\section{Rasgos esenciales del personalismo}

Empezaré, pues, recordando algunos trazos esenciales de un pensamiento personalista como el concepto de persona. Según Mounier, ¿qué significa ser persona? ¿Qué significa decir que el hombre es una persona? A su entender quiere decir que consideramos al hombre como una substancia espiritual, capaz de actuar a partir de una escala de valores que él mismo ha asumido. Es un concepto, por tanto, que viene de lejos aunque recibe matices de nuestro tiempo, ya que la concepción del hombre-persona tiene una historia más reciente en la filosofía occidental que la consideración del hombre-individuo. Por un lado, nosotros somos herederos de la metafísica aristotélica que es la que consideró al hombre desde su naturaleza genérica y construyó su consistencia a partir del concepto de sustancia. Esta consistencia se refleja en el aspecto de res o "cosa», que asimila la realidad del hombre a cualquier otra realidad consistente $y$, al mismo tiempo, su naturaleza propia le distingue de ella. Sin embargo, el concepto de persona encuentra sus orígenes en la llegada del cristianismo, que abre al reconocimiento de la dimensión espiritual de la vida humana, ya que la fe cristiana está preñada de un mensaje de dignidad de la vida humana al reconocer la existencia de cada persona como única y querida por Dios, que le otorga el carácter de hijo. Boecio fue el primero que corrigió la concepción aristotélica del hombre aplicando el carácter de persona a cada individuo humano, reconociéndolo como una sustancia única de naturaleza espiritual. La escolástica medieval continuó aplicando este concepto de persona dentro de un esquema metafísico que seguía en gran medida la concepción de los antiguos.

Con la llegada del Renacimiento el hombre experimentó un ensanchamiento de su espíritu hasta captar sus aspiraciones infinitas que, por primera vez le hacían sentir la inmensidad de su valor y la filosofía moderna consiguió interiorizar el arraigo de todos los problemas en un sujeto pensante. Por esta vía encontraremos por primera vez la aplicación del concepto de persona a la dignidad única de cada ser humano, en la filosofía crítica de Kant, cuando en el momento de descubrir qué es una conciencia moral, encuentra que es una persona, es decir que es un fin en sí misma y no puede convertirse en medio para ninguna otra finalidad que no sea ella misma. Desde la filosofía de Kant la dignidad del hombre queda establecida como base de cualquier comportamiento ético y como condición de cualquier sociedad humana. Con las filosofías de la existencia que se presentan a partir de Kierkegaard se irá perfilando el carácter único de la vida del hombre y de rebote su valor. Las filosofías de un pensamiento reflexivo, como el de Main de Biran, de Bergson o de Blondel, irán profundizando también en la naturaleza de tal intimidad humana. Llegamos de esta forma a las puertas del siglo XX, en 
que aparece un pensamiento personalista más explícito. Las filosofías de aspecto dialógico, como las de Buber, Ebner o Rosenzweig, o las filosofías nacidas de un contexto más existencial, como las de Marcel, Jaspers o Berdiaev, precederán la aparición de los pensadores propiamente personalistas como Mounier, Nabert, Lacroix, Nédoncelle o Landsberg. Y, más cercanos a nosotros, podríamos citar Lévinas, Ricœur y Marion. Desde el pensamiento de todos estos autores se hace notar que la marca distintiva de la persona es su cualidad subjetiva, su existencia libre i abierta, capaz de desarrollarse y de integrar progresivamente todas sus virtualidades. Ellos le reconocen una libertad de iniciativa capaz de responder a las interpelaciones que le llegan, guiándose por una escala de valores voluntariamente aceptada y asumida. Todas estas vivencias integradas por una existencia consciente de sí misma se convierten en signos de identidad capaces de dar razón de la realidad única de aquel sujeto, realidad que se articula alrededor del nombre propio.

Vemos este concepto de persona como contrapuesto al concepto de individuo, que es puramente cuantitativo y sólo singulariza a un miembro de la especie humana y, por tanto, no refleja el carácter único y espiritual de la persona. La individualidad del singular implica que es intercambiable entre los innumerables miembros de una pluralidad. Desde el punto de vista social, esta agrupación de una pluralidad de individuos se tipifica como una masa, un montón de gente sin nombre, en la cual se ha disuelto la verdadera singularidad personal. Así, los asistentes a un espectáculo, como por ejemplo los de un partido de fútbol, forman un grupo compacto en el cual las características que identifican a cada uno de los integrantes son insignificantes. Cada individuo cuenta únicamente desde el punto de vista numérico, hasta el punto de que su carácter propio, aquello que constituye su verdadera identidad es indiferente, es decir, no permite diferenciarlo de los demás. Cuando hacemos la descripción del grupo a partir de los individuos, sólo los contamos, hasta el extremo de que se pueden substituir los unos por los otros. Lo que pretende el grupo asociativo es una finalidad externa a sus miembros y se puede conseguir sin que repercuta en su realización. No ocurre lo mismo con la consideración del hombre como persona, ya que este concepto implica que cada uno manifiesta aquello que le es más propio, su carácter único e insustituible, que es el verdadero rasgo de la identidad. Como veremos, el carácter incluye todos los elementos diferenciales naturales y adquiridos por el propio trabajo de la persona $y$, por tanto, asumidos voluntariamente.

Desde el punto de vista social la persona se integra en una comunidad, en la que cada uno disfruta de un nombre y en la cual se le reconoce su lugar, de manera que se convierte en única e insustituible. La comunidad es como una persona de personas construida por las relaciones recíprocas de los unos con los otros. Así 
pues, la presencia y la acción del hombre-persona se convierte en esencial para la existencia de la comunidad. Las relaciones entre los miembros de la comunidad son determinantes de manera que cada uno cuenta para el conjunto de la comunidad, su influencia repercute en la vida de los demás, de manera que su presencia se deja notar. La finalidad de la comunidad se encuentra en ella misma y no puede ser conseguida sin que las personas la consigan también.

La naturaleza de la filosofía que se puede hacer cargo de la persona es distinta de la filosofía en uso en la tradición occidental. Si el estilo de filosofía se reconoce por el tipo de pregunta que formula, hay que considerar que la filosofía de la tradición occidental está determinada por la interrogación: ¿̇qué es eso? Es una pregunta que ya orienta la respuesta hacia la cosa, de manera que ya sabemos qué respuesta obtendremos. La pregunta se dirige ya a una naturaleza neutra, que no puede responder por sí misma. En consecuencia, es una pregunta que lleva a una respuesta de base materialista, porque la cosa no dispone de ningún tipo de iniciativa. El filósofo no aspira a otra cosa que a determinarla y clasificarla en un marco de entidades jerarquizadas, como por ejemplo un naturalista que clasifica los insectos en un insectario o las hierbas en un herbario. Sin embargo, abordar la cuestión de la persona exige otro tipo de filosofía. Tiene que emitir una pregunta pertinente dirigida a un ser vivo, un ser con iniciativa y que se posiciona diferentemente según la relación que establece. Como que no se trata de una cosa, la pregunta pertinente que se le debe dirigir no es: ¿qué es, esto? sino ¿quién eres? Así pues, es el quién y no el qué lo que hace que la pregunta se abra a una interrogación personal. La pregunta no se dirige a una naturaleza neutra, que no puede responder desde ella misma, sino a un ser vivo de quien se espera una respuesta directa venida de él mismo. En realidad se trata de una interpelación.

Como decía Buber, la forma pertinente de llegar al otro no es plantear la pregunta en tercera persona sino en segunda persona, es decir, reconociendo la presencia de un tú, cosa que supone la existencia de una estructura de diálogo. Llegados a este punto, tendríamos que desear que una filosofía distinta, en gran parte todavía por hacer, respondiera a este segundo tipo de preguntas, no a las preguntas del qué, sino a las preguntas del quién. La filosofía occidental, especialmente desde la Modernidad centrada en el "yo pienso» cartesiano, ha partido de un centro único a partir del cual se construye un sistema también único. La posibilidad del reconocimiento de la persona del otro posibilita un pensamiento con dos centros, construido como una elipse a partir de sus dos focos, una filosofía de largo recorrido de carácter hermenéutico, que permita interpretar un pensamiento a partir de un otro y que se abra así al pluralismo. Esta es la filosofía que creemos que se encuentra en la base de la interpretación de la realidad de la persona. Una 
invitación a leer la realidad de una manera distinta la brinda Lévinas cuando dice que existen dos interpretaciones de la realidad: la objetiva, de las cosas, y la subjetiva, de las personas. Una interpretación de la realidad sólo desde el aspecto objetivo marcaría el verdadero dominio de lo que él llama materialismo, es decir, la filosofía de lo neutro, donde nada dispone de iniciativa; esta filosofía no puede alcanzar el nivel personal porque se queda siempre en una interpretación neutra de la realidad, en la que la persona ha sido también neutralizada. En cambio, la interpretación de la realidad desde la existencia del sujeto correspondería a una verdadera filosofía personalista.

Aquí hay que hacer una aclaración fundamentada en la distinción que hace el filósofo Wilhelm Dilthey entre los conceptos de explicación y comprensión, que están en la base de la distinción entre la metodología de las ciencias de la naturaleza y la metodología de las ciencias del espíritu. La filosofía hermenéutica analiza la objetividad de la vida humana a partir de la conciencia histórica, pero la historia sólo puede ser comprendida a partir de las otras conciencias en continua conexión con ellas. Esta aclaración era necesaria porque la pregunta per el hombre que nos hemos propuesto desde el principio no puede tener una aproximación descriptiva, como la que la ciencia hace sobre un objeto de la naturaleza, en la cual el conocimiento aspira a la captación completa de su objeto a través de la explicación. La aproximación al conocimiento de la persona sólo puede ser comprensivo, en el sentido que Dilthey da al término comprensión, que implica interpretación y empatía de aquello que no se puede poseer. La vida del hombre es libre y se nos escapa. No puedo poseer su realidad porque está en cambio constante y, en tanto que es una realidad viviente, no puede ser abarcada. Siempre es más de lo que el conocimiento pueda captar. Pretender atraparla en un concepto equivale a reducirla a cosa, a etiquetarla, y por tanto, a falsear su realidad personal. Así pues, ningún concepto puede definir la persona, ni podemos abrazarla sin falsear su realidad. ¿̇Cuál es, pues, la realidad de la persona? La persona es realmente indefinible, porque por esencia está abierta al infinito y su vida se desarrolla con un progreso ilimitado. Sin embargo, está situada en la finitud y sus límites verdaderos se manifiestan en el momento de la muerte. Es el momento en que acaba su progresión, de manera que, sólo entonces, podríamos definirla, si realmente conociéramos la totalidad de su ser. Pero tal realidad se nos escapa en aquello que la persona tiene de libre y de íntimo. Comprender el ser de la persona se convierte en una tarea difícil, incluso para uno mismo. La pretendida claridad del «cogito» cartesiano, que permitía un reconocimiento inmediato en la claridad y la distinción de un brillo evidente, se convierte en oscura cuando en el cogito humano se mezclan lo desconocido, lo inconsciente y lo incontrolado, que traducen la naturaleza del ser humano como algo quebradizo. El esfuerzo por identificarnos 
e identificar a los demás se convierte en un proceso difícil y penoso. En el fondo de la pregunta "¿qquién soy?» o "¿quién eres?» se encuentra una respuesta, pero Ricœur nos recuerda que tal respuesta no es fácil:

La vida, al menos en su estadio humano, es una situación compleja y enredada, un problema no resuelto, los términos del cual no son ni claros ni concordantes. Por eso se trata de una cuestión abierta dirigida a la voluntad: por eso hay un problema de elección y un problema moral. ${ }^{6}$

\section{La condición humana}

En efecto, avanzamos a través de intuiciones sobre la condición humana que consideramos esenciales y que se inspiran en las aportaciones de Buber, Rosenzweig, Mounier, Nédoncelle, Berdiaev, Marcel, Ricœur, Lévinas o Marion. Todos ellos se confrontan con un acceso a la persona que no sea objetivo, que no reduzca la persona a objeto, o que pretenda más explicar que comprender. Para no quedar, pues, atrapados en un mundo objetivo, conviene un momento voluntario y una elección que nos permitan acceder al otro no con una actitud cualquiera sino con una actitud purificada per un respeto ético. Hace falta un hombre despierto, una relación personal, un respeto por el rostro del otro, un camino ético, para situar al hombre en su verdadera perspectiva. Se trata de un acceso que reconoce la personalidad del otro y que establece una relación verdaderamente humana en la cual el otro no es una cosa sino una persona portadora de un nombre. El otro sólo puede ser abordado nombrándolo. El nombre es lo que tiene de más propio y es lo que le identifica. Nombrarlo es entrar en relación con él, aunque no sea todavía un conocimiento. Nombrar al otro es interpelarlo, llamarlo, pero no es definirlo. Recordemos solamente cómo los nombres en algunas culturas, como la cultura bíblica, pretendían ser explicativos de la propia realidad. Con todo, esta interpretación era más un intento que una realidad. Así pues, esta identificación a través del nombre no queda tampoco exenta de problemas.

\section{I. La humanidad del "sí mismo"}

Para afrontar la dificultad de la identidad personal Paul Ricœur propondrá lo que él llama la hermenéutica del sí mismo, que presenta en su obra Soi-même comme un autre. Se trata de un estudio profundo a través de las principales corrientes del

${ }^{6}$ RICOEUR, P. Voluntario e Involuntario, op. cit., p. 115. 
pensamiento actual para encontrar el hilo conductor de un sujeto que es conciencia y que no se presenta desde la figura epifánica del yo, sino desde la actitud reflexiva del símismo. Decir quién es este sí mismo no tiene una respuesta inmediata, como pretendía la evidencia del cogito cartesiano, sino que implica un largo camino a través de su decir, de su actuar, de su narrarse y de su comportarse de una manera moral. Cuando Ricœur encara el tema de la identidad de este sí mismo, muestra que la existencia humana se interpreta en dos niveles diferentes de identidad: por una parte lo que él llama identidad-idem (mêmeté-sameness-Gleichkeit) y por otra la identidad-ipse (ipseïté-selbshood-Selbstheit). La primera se determina sobre la base de la sustancia, que se presenta con unos trazos invariables que la identifican; la segunda se manifiesta desde el reconocimiento interior, que se testifica a partir de la palabra dada y del mantenimiento de las promesas.

El problema entre ambas identidades sólo surge cuando aparecen las consideraciones temporales de la existencia personal, ya que es en el hecho de la permanencia en el tiempo donde se confrontan las dos interpretaciones. El conjunto de rasgos personales que manifiestan una identidad, como pueden ser los datos que aparecen en mi tarjeta de identidad -nombre, apellidos, fecha y lugar de nacimiento, sexo y filiación- constituyen las coordenadas espacio-temporales que determinan el lugar de una persona. Las instituciones del Estado que han de controlar la identidad de los ciudadanos se pueden fijar todavía en otros elementos que lleguen a determinar la identidad de alguien con toda precisión, sea por las huellas digitales, el fondo del ojo o, incluso, el código genético. Pero se trata de una identidad puramente externa y que, aunque nadie más pueda suplantar nuestro lugar, no estaría enriquecida por elementos propiamente interiores. Todos aquellos elementos de mi identidad son externos a mí mismo y, por más que queden señalados por las marcas de mi físico, son cambiantes en el curso del tiempo. El peso, la altura, la figura o el color de los cabellos son rasgos que nos inscriben en el mundo de los vivientes y que están sometidos a los avatares del tiempo: en efecto, podemos engordar, adelgazar, teñir nuestro cabello, incluso sufrir un accidente que nos desfigure y dificulte el reconocimiento de nuestra identidad. Sin embargo, siempre dispondremos de elementos para mantenerla: pensemos en los casos límite de los campos de concentración, donde toda la identidad de los allí confinados quedaba reducida a un número marcado en la piel, la cual cosa implicaba un grado extremo de degradación en el reconocimiento humano. La «identidad ídem» es pues un primer escalón en el reconocimiento de la individualidad, ya que los elementos descriptivos que la constituyen permiten señalar a una persona única entre una multitud. Ahora bien, todos aquellos rasgos son repetitivos y se podrían reproducir de una persona a otra hasta producir confusión. De hecho, se pueden reproducir o simular, como en los intercambios de identidades que se han visto en 
las astucias del espionaje o bien se pueden multiplicar tal como lo preconiza una educación masificada, que pretende la producción de un cierto tipo de alumno. La biogenética presenta la posibilidad del caso extremo de la clonación que implica la multiplicación indefinida de una identidad. Los relatos de ficción proponen también otra paradoja, la de un hombre sin atributos $y$, por tanto, sin posibilidad de identificarlo. Robert Musil dejó un relato insólito sobre un individuo que opta por disolver su yo y aceptando ser muchas cosas a la vez. ${ }^{7}$ Dereck Parfitt con su laboratorio de ciencia-ficción también pone a prueba la identidad en unos casos en que fracasan todos aquellos criterios $y$, como consecuencia, preconiza que la libración del yo es benéfica para la vida humana. Así pues, hay que profundizar algo más en la naturaleza de aquella identidad-ídem.

En efecto, si observamos bien la identidad-ídem nos daremos cuenta de que incluye diversas relaciones. Este principio confirma el carácter relacional de la identidad que Kant ve integrar-se en la categoría de la sustancia. En primer lugar, podemos hablar de una identidad numérica que hace que dos manifestaciones de una cosa designada por un nombre invariable no hacen propiamente dos cosas sino una sola. Identidad significa aquí unicidad y a esta relación le corresponde la operación de la identificación que convierte el conocer en un reconocer: la misma cosa, dos veces, $n$ veces. En segundo lugar, podemos hablar de identidad cualitativa, es decir la semejanza extrema entre dos realidades las hace intercambiables, como por ejemplo dos personas que van vestidas igualmente las podemos intercambiar una por la otra. A esta relación le corresponde la operación de la sustitución. Ahora bien, ambas identidades pueden inducir a duda cuando se interpone el tiempo entre dos manifestaciones de la misma cosa, especialmente cuando están separadas por una gran distancia. Así, saber que el hombre que está ante un tribunal y el autor de un presunto crimen sea la misma persona puede quedar sin respuesta. A primera vista parece por tanto que la cuestión de la permanencia en el tiempo afecte a la identidad-idem. Por este motivo, hay que invocar un tercer criterio de la noción de identidad, la continuidad ininterrumpida entre el primero y el último

\footnotetext{
${ }^{7}$ MusIL, R. (1997) El hombre sin atributos (1930-1942). El hilo argumental de El hombre sin atributos es muy simple. En 1913, un año antes de empezar la gran guerra, comienza la preparación del séptimo jubileo de la coronación del emperador Francisco José, que tenía que celebrarse en 1918. El narrador lo explica desde el punto de vista de quien ya sabe que la pretendida celebración del imperio acabará en necrología. La disolución del marco político colectivo es anticipada por la decisión del protagonista, Ulrich, de disolver su propio yo: porque no sabe qué hacer con sus talentos de hombre moderno, Ulrich (trasunto del autor) prefiere parecer muchas cosas antes que definir su propio ser. En aquel panorama del ocaso definitivo del mundo y del sujeto se intercalan una multitud de episodios, observaciones y argumentos paralelos que quedan reflejados en la conciencia del protagonista. El único refugio que éste encontrará será el amor transgresor por su hermana.
} 
estadio del que consideramos el mismo individuo. El tiempo, efectivamente, ha actuado como un factor de desemejanza en el individuo, que ha envejecido, ha madurado o, simplemente, ha enfermado. Teniendo en cuenta que el tiempo se convierte efectivamente en una amenaza para el reconocimiento de la identidad, no podemos superar esta dificultad si no se supone en la base de todos aquellos cambios un principio de permanencia en el tiempo.

La noción de la identidad-ipse implica una forma de permanencia en el tiempo que no se reduce al esquema de la sustancia. En efecto, hablando de la existencia humana disponemos de dos modelos de permanencia en el tiempo que no son reductibles a la sustancia: el carácter y la palabra dada. Ricœur entiende por carácter el conjunto de marcas distintivas que el individuo humano ha elegido a través de su propia existencia y que permiten identificarlo como él mismo. En la medida que el carácter refleja la existencia de una persona única podemos llamarle personalidad. Estamos de acuerdo con Ricœur que el carácter ha sido configurado por la secuencia de una vida y ha sido asumido libremente por una voluntad activa: ha sido forjado por actos, sucesos, vivencias, pasiones y determinaciones que constituyen una identidad de otro tipo que la identidad-idem ya que está caracterizada por la fidelidad a sí mismo. No obstante, además del carácter existe otro modelo de permanencia en el tiempo: se trata de la palabra dada y mantenida, entendida como una actitud de fidelidad prolongada. Por eso, mantener la palabra dada implica también una permanencia en el tiempo. En un cierto sentido, es como un reto que se debe afrontar, una voluntad de no cambiar, una promesa mantenida que pide una justificación ética. No hay que dudar, pues, de que este segundo tipo de identidad, la identidad-ipse, tiene una cualidad superior a la primera, ya que por ella la persona se hace merecedora de confianza. Potencialmente todos los individuos están destinados a adquirirla, pero no todos lo consiguen. A veces la vida de algunas personas queda como recortada y de la ipseidad no queda más que su aspecto originario y primitivo como la afirmación egocéntrica de sí mismo.

\subsection{La identidad narrativa}

En consecuencia, la identidad-ipse que se describe aquí queda alejada de la identidad-ídem de manera que entre una y otra se abre un intervalo de sentido que hay que llenar. Ricœur considera que la «identidad ídem» y la «identidad ipse» son como los dos polos de una tensión dialéctica entre los cuales se encuentran los humanos en todas las situaciones intermedias. El pensamiento de Ricœur se vuelve aquí enormemente fecundo, ya que por el camino de una hermenéutica del sí mismo, ha conseguido situar aquel punto medio en el cual se encuentra el 
hombre y ha intentado formular la gramática para poderlo describir. El largo recorrido del pensamiento de Ricœur ha pasado por la fenomenología, la simbólica, la hermenéutica del psicoanálisis y la hermenéutica de las religiones, el estudio de las figuras literarias y la narratología, hasta expresar la existencia humana en términos narrativos. En primer lugar, el estudio de la metáfora, como incorporación de un nuevo sentido a la expresión poética, le ha permitido captar una realidad que todavía no ha sido dicha, adivinando un camino hacia la comprensión de lo real; y, en segundo lugar, el estudio de la narración le ha permitido interpretar la vida humana como si se tratara de un relato que se está configurando. Da nacimiento aquí al concepto de identidad narrativa que traduce la identidad personal en un relato que se extiende de la vida a la muerte y que se ha construido con todas las vivencias positivas y negativas, asumidas e inconscientes, activas y pasivas, que constituyen el hilo de la vida: que un tal relato sea más o menos ordenado dependerá de la puesta en intriga a través de la cual el sujeto quiera darle forma. La identidad narrativa que expone la vida humana como un relato de sí mismo constituye para Ricœur el puente que buscaba entre la identidad ídem y la identidad ipse. La mediación entre los dos extremos del carácter y de la palabra dada y mantenida por la promesa, dice el autor, ha de ser ocupada por la noción de identidad narrativa, que oscila entre los dos límites, el inferior donde la continuidad en el tiempo expresa la confusión entre el ídem y el ipse, y un límite superior donde el ipse cuestiona su identidad sin la ayuda y el apoyo del ídem.

Llegamos al final de esta primera reflexión sobre la identidad humana. La filosofía personalista permite mostrar un modelo que interpela la acción educativa muy de cerca. Por eso me gustaría acabar dejando unas cuestiones abiertas al debate: ¿a dónde nos ha conducido, esta reflexión sobre la identidad personale Parece que el hombre y la mujer emergen como personas desde la vivencia de su existencia humana como conciencias de sí mismo, reflexivas, i lo hacen en el seno de una comunidad. Ello significa que hay que considerar a las personas en relación con otras personas y es en estas relaciones donde se enriquecen o empobrecen su propio reconocimiento y su propia autoestima. En el seno de aquella comunidad y en relación con su propio ser es donde crecen, es decir, experimentan la emergencia de su libertad y de una conducta más autónoma. En este contexto nos hemos de preguntar cuál es el ambiente educativo que favorece la eclosión de esta persona libre y autónoma y cuál es el ambiente que la dificulta.

La consolidación de la persona supone la confirmación exitosa de su crecimiento. Ante la posibilidad de la disgregación o atomización de todos los elementos constitutivos de la vida humana, que es la consecuencia de vivir sin cuidado, el progreso de la persona implica la integración positiva de la existencia. Eso exige 
una asunción de la propia vida a partir de un núcleo de conciencia que reconozca su vida como propia. Asumir la propia vida pasa por estar presente a los acontecimientos que se producen en el espacio y en el tiempo en los que el hombre vive arraigado. Pero pasa también por asumir los propios actos y las propias decisiones a partir de una voluntad que tome en mano la propia vida, reconociendo y aceptando pacientemente las adversidades y asumiendo la responsabilidad para intervenir. De esta forma la vida humana incluye saber gozar con alegría y saber encajar los contratiempos, saberse capaz de certezas, dudas y errores. Por tanto, la acción educativa ha de ser integradora y no atomizadora, haciendo nacer una conciencia sólidamente humana.

Ricœur ha descrito la realidad de la persona como una identidad narrativa y ello implica que hay que construirla de tal manera que pueda ser leída. La identidad narrativa se extiende entre dos extremos: por un lado los rasgos de nuestro carácter y por otro las fidelidades a nuestros proyectos y a nuestras promesas. Pero hay que dar unidad a este vivir para que no sea un vivir disperso, que pueda tener aquella puesta en intriga que Aristóteles deseaba para la buena narración. Este orden ha de hacer posible entender qué hacemos a partir de lo que nos proponemos para que nuestra vida sea coherente. Como dice el poeta Kavafis, la vida es como un camino de retorno hacia la propia ĺtaca, y hay que enriquecerlo por el bagaje vivido, colmado de vivencias prometedoras. Eso implica el paso por el mundo de la cultura, por el asentimiento a nuevos conocimientos, por la creación de nuevas relaciones y por la aventura de un camino lleno de realidades y fantasías que nos han hecho crecer. ¿̇Cuáles son los compañeros de ese viaje, cuáles las experiencias enriquecedoras, cuáles los relatos vivos o de ficción que nos llenarán de palabras y de ideas? ¿¿Qué argumentos harán posible que elijamos lo bueno y que rechacemos lo menos bueno para que nuestro espíritu sea tan libre para escoger lo que conviene como crítico para rechazar lo inconveniente?

El elemento central de la narratividad es la marca de la condición humana, que ha de habitar en el tiempo. Tiene que afirmar su permanencia entre los dos momentos extremos de su vida, que son el nacimiento y la muerte. Del primero no tiene conciencia alguna ni la tendrá tampoco del segundo, pero el hombre reconoce su existencia como alargándose en el tiempo. Y en el interior de esa existencia se perpetúan los recuerdos y avanzan los proyectos, no como si se tratara de una cadena rota de momentos sino como la unidad de un relato que hay que asumir en su totalidad. El carácter temporal de la vida humana manifiesta dos aspectos inseparables: por un lado su presencia, como voluntad de ser persistente a lo largo del contínuum vital, y que aspira a prolongarse más allá de la muerte, y por otro, su provisionalidad, como reconocimiento del carácter efímero de todos 
los momentos vividos y como amenaza de caducidad de la totalidad de la vida. Una tal duplicidad de la vivencia del tiempo nos hace posible abrirnos también a dos posibilidades que son opuestas aunque no son incompatibles. La posibilidad de la esperanza de una continuidad más allá de la muerte y la posibilidad de la angustia ante la nulidad que muestra la caducidad de la vida. El planteamiento de la cuestión resulta imposible de esquivar, de manera que no se la puede banalizar con una existencia constantemente distraída que impida vivir el grueso del tiempo. La humanidad de una vida plenamente asumida implica afrontar su carácter provisional y aceptar su término para completar entero nuestro propio relato. En consecuencia, para que nuestro relato tenga sentido, hay que encontrarle un sentido al tiempo e iluminar así la totalidad de la vida.

\section{El hombre es acción}

\section{I.Aristóteles}

La obra de Ricœur Soi-même comme un autre acaba intentando trazar una ontología de la persona. Su proyecto es también el nuestro para que podamos finalmente disponer de un esquema de interpretación de la vida humana. Ricœur tiende a buscar complicidades en los filósofos clásicos, porque eso le permite encontrar elementos para avanzar en su propia investigación. Lo seguimos también en eso para introducirnos en un esquema ontológico diferente de la metafísica aristotélica de la sustancia. En principio parece que Aristóteles se inclinaba más por la contemplación como la actitud más digna del filósofo, ya que identificaba mejor la vida del hombre libre, la "theoria" es lo que acerca más la vida del hombre a la vida de Dios; en cambio, deja la acción como aquello que corresponde más a los esclavos que están al servicio del sabio. La "praxis" identifica la vida humana a ras de tierra, con una dignidad inferior a la contemplación. Quizás sea éste el motivo que impidió que Aristóteles construyera una verdadera filosofía de la acción. No obstante, nos recuerda Ricœur, el mismo Aristóteles ya había dicho que el ser puede ser dicho de muchas maneras y que, en consecuencia, se podrían estructurar diversas ontologías en torno al ser. Aunque Aristóteles privilegió la metafísica de la sustancia, dejó otra esbozada a partir de la noción de acto. Y es justamente desde este punto de vista como quisiéramos enfocar nuestro discurso.

En efecto, el acto es para Aristóteles un aspecto a través del cual pretende presentar al ser. No se satisface, pues, con mostrarlo a partir de su pasividad o de su 
carácter sustantivo, como base de sostenimiento del ser que es, sino a partir del aspecto dinámico, que le posibilita explicar el movimiento de las cosas naturales y a la vez la estructura del ser vivo. Aristóteles era hijo de un médico y un gran observador de la naturaleza. De ahí su admiración por el cambio de las cosas, especialmente por el cambio en los seres vivos, era un enigma que le inquietaba y que quería resolver. Más aún después de que los filósofos de Elea e incluso su maestro Platón habían condenado el movimiento al terreno de lo inexplicable. Aristóteles aceptó el reto de buscar la racionalidad del movimiento, pero si quería encontrarla tenía que aceptar que la explicación del cambio se producía sobre la base de una permanencia.

El acto es la instancia plena del ser, la que realiza la naturaleza de las cosas, por lo que coincide con su carácter esencial. Sin embargo, el acto señala su aspecto dinámico, motriz, realizador, confrontado a lo que Aristóteles llama la potencia, que sería el aspecto pasivo, propiamente inexistente, pero necesario para recibir la realidad. Las cosas son en realidad un mixto compuesto de acto y potencia. De esta manera el movimiento $y$, también la vida, se explican como el dinamismo que va de la potencia al acto, pero que se realiza justamente a partir del acto, que es el aspecto realizador. De repente, el mundo inerte de las sustancias, cobra dinamismo y se convierte en vivo. Esta intuición aristotélica que abría un camino prometedor a la filosofía quedó desgraciadamente postergada en favor de la metafísica de la sustancia, que privilegió en consecuencia el aspecto definidor y clasificador de la realidad.

\subsection{Espinosa}

Dejemos pasar unos cuantos siglos hasta encontrar una aportación filosófica interesante para definir el carácter activo de la vida humana. Nos detenemos en el siglo XVII para presentar el pensamiento de Baruch Espinosa (1632-1677), un judío perseguido incluso en su país, Holanda, que era el más liberal de su época. Fue un hombre que se dedicó a propagar una filosofía de confianza en el orden de la naturaleza y en el carácter divino de todo lo real. Personalmente, nunca dejó de vivir una vida libre, honesta, sencilla, alegre y confiada en un mundo que era todavía tributario de las violencias y de las intolerancias. Llevar esta vida tranquila no suponía en él ninguna pasividad ni resignación, a pesar de considerar que todo lo real forma parte de una única sustancia, que es la naturaleza y que es Dios. Sylvain Zac afirma que podemos centrar todos los temas espinosistas alrededor de la noción de vida. La vida para Espinosa se muestra como potencia, como queda de manifiesto en su Ética. Ahora bien, esta noción no ha de ser comprendida como 
pasividad contrapuesta al acto, como hemos visto en la teoría de Aristóteles, porque la noción de potencia aparece detrás de cualquier idea de forma y se aplica al hombre como a cualquiera otra cosa. En este sentido, Espinosa concibe al hombre como una fuerza, un dinamismo, que él llama "conatus", considerado como un esfuerzo por perseverar en su ser. Espinosa mismo afirma que Cada cosa en tanto que es en ella se esfuerza en perseverar en su ser. ${ }^{8}$ Dicho de otra manera, eso implica tener un carácter vivo que, en la medida en que el hombre es consciente de ello, podemos llamar deseo. La existencia del "conatus" se convierte en un tema central en la filosofía de Baruch Espinosa. Para fundamentar esta afirmación, presenta algunos razonamientos. En primer lugar, las cosas particulares son, según lo que propone, manifestaciones de Dios; y eso significa que cada uno expresa el poder de Dios de una forma particular.

En efecto, las cosas singulares son modos por los cuales los atributos de Dios se expresan de una manera cierta y determinada... es decir... cosas que expresan el poder de Dios de una manera cierta y determinada. ${ }^{9}$

Más aún, nunca puede formar parte de la definición de Dios que sus formas se contradigan entre sí; por tanto, cada cosa se opone a todo lo que la aleje de su existencia. Una tal resistencia a la destrucción la formulaba basándose en un esfuerzo continuo para existir y "conatus" es la palabra que más utiliza para describir aquella fuerza. Por otra parte, también usa el término "conatus" para referirse a un concepto rudimentario de inercia. Como ninguna cosa puede ser destruida sin la intervención de fuerzas externas, el movimiento y el reposo, existirían indefinidamente si no fuesen perturbados. Esforzarse en perseverar no es meramente algo que una cosa hace además de otras actividades que podría emprender; sino que constituye la esencia actual de una cosa. Algunos estudiosos de Espinosa interpretan esta frase en el sentido de que una cosa en el fondo no es nada más que el "conatus".

Con su determinismo, cree que el ser humano y la naturaleza han de estar unidos bajo las leyes; teniendo presente que Dios y la naturaleza son una misma cosa, no existe el libre albedrío. Su pensamiento propone proveer de una explicación unificada para todos esos elementos dentro de un marco naturalista en el cual el "conatus" sería la idea central. Por ejemplo, una acción sería «libre», sólo si surgiera de la esencia del "conatus" de una entidad. No puede darse una libertad absoluta e incondicionada de la voluntad, porque todos los sucesos en el mundo natural,

${ }^{8}$ EsPINOSA, Ética, libro I, proposición VI.

${ }^{9}$ Espinosa, Ética, libro I. 
incluidas las acciones y decisiones humanas, vienen determinadas de acuerdo con las leyes naturales del universo, de las cuales nada puede escaparse. A pesar de eso, una acción puede ser considerada libre en el sentido de que no está sujeta a fuerzas externas. Los seres humanos forman parte de la naturaleza y, por tanto, la conducta humana es natural y racional y estaría motivada por el "conatus".

El hombre es, pues, este impulso que no es ciego porque está sometido a la razón, y en la medida de que esta le ilumina se hace consciente de su pertenencia al orden del todo, un orden que tiene un carácter geométrico. Este paso de la ceguera a la razón, que sucede en la conciencia del hombre, es también un paso de la pasividad a la acción. La acción que se acomoda con justeza al orden del todo y en la medida en que es consciente de él, es vivida alegremente como un amor intelectual de Dios. Una acción capaz de buscar el orden y de vivir gozosa dentro del orden. El dinamismo del viviente excluye, pues, cualquier iniciativa que quisiera romper el orden de la naturaleza. Así el esfuerzo por el cual cada cosa se esfuerza a perseverar en su ser no es nada fuera de la esencia actual de aquella cosa. ${ }^{10}$ La posibilidad para nosotros de ser verdaderamente activos se encuentra en el paso que tenemos que hacer de las ideas inadecuadas a las adecuadas. Esta conquista de la actividad en la búsqueda de las ideas adecuadas es lo hace que toda la obra de Espinosa se convierta en una ética.

¿Qué conclusiones saca Ricœur del paso por la filosofía de Espinosa, que nosotros hemos sobrevolado brevemente? Por una lado, que aquel "conatus" que es general en todos los seres de la naturaleza se hace más legible en el hombre; por otro, que cualquier cosa expresa en grado distinto el poder de la vida que para Espinosa es vida de Dios. Ricœur concluye que la conciencia no es, como en Descartes, el punto de partida claro y distinto, sino que implica un largo desvío. La prioridad del "conatus" es quien impone a la conciencia adecuada este largo desvío. Sylvain Zac piensa que en el largo retorno que Ricœur impone al "cogito" roto, Espinosa tiene el mérito de haber articulado el "conatus" sobre el ser activo y potente que él mismo denomina "essentia actuosa".

\subsection{Arendt}

Hay que reseguir, pues, el hilo de una filosofía de la acción para poder describir mejor la vida humana. Llegamos así a nuestro tiempo en que el tema de la acción ya ha sido abordado por muchos filósofos, pero el pensamiento que presenta

${ }^{10}$ EspinOSA, Ética III, proposición VII. 
Hannah Arendt en el conjunto de su obra y en su libro La condición humana se hace más concreto. Discípula de Husserl y formada en la escuela fenomenológica de Heidegger, el pensamiento de esta mujer judía se encarna en la historia y analiza la vida del hombre con una finura extrema. El título del libro ya sugiere que Hannah Arendt no aborda el tema desde conceptos esencialistas que intentaran escaparse de la historia concreta del hombre y de su inserción en el tiempo, por eso prefiere hablar de la condición humana. En efecto, el sujeto humano vive inmerso en una realidad que le supera y que lo somete a violencias envilecedoras. ¿Cómo puede llegar a comprenderse a sí mismo? Arendt piensa que el hombre sólo puede llegar a comprenderse a través de la acción, y la inmortalidad que busca pasa por el descubrimiento de su vida activa. La opción de Hannah Arendt supone una valoración diferente de la que hacía Aristóteles respecto de la prioridad de la vida contemplativa. Este consideraba la superioridad de la vida contemplativa porque era propia de los hombres libres que no estaban vinculados al trabajo de los esclavos, unido a la transformación de la naturaleza. Arendt cambia el signo de esta valoración de los antiguos al proponer una interpretación de la vida humana desde la vida actuosa. Por ello se dispone a describir en su libro los tres tipos de actividad fundamentales que corresponden a las tres actitudes diferentes según las cuales el hombre vive en la tierra: el trabajo, la obra y la acción. ${ }^{11}$

El trabajo es la actividad que corresponde al proceso biológico del cuerpo humano. Su crecimiento, metabolismo y decadencia están ligados a las necesidades vitales producidas y alimentadas por el trabajo en el proceso de la vida. La condición humana encuentra en el trabajo la razón de ser de la vida misma ya que el fruto del trabajo está destinado a ser consumido para mantenerla. En la época antigua el trabajo era una actividad menospreciada y su relación con la tierra lo convertía en propio de esclavos a quienes tocaba la realización del trabajo, considerado como una actividad penosa que implicaba esfuerzo y fatiga. La etimología de trabajo ya lo sugiere, porque proviene de la palabra latina "tripalium", que significaba los tres palos a los que iban atados los bueyes que tiraban del carro. Pero también gracias al trabajo se obtenía la riqueza que algunos acumulaban, acaparando así el fruto de un trabajo que no había hecho sudar sus frentes. En realidad se trata del éxito del "animal laborans" que sólo busca satisfacer sus necesidades para ser feliz. En la modernidad, se produce un cambio en la valoración del trabajo, que deja de ser considerado como una tarea penosa para convertirse en el auténtico elemento transformador de la realidad, de la naturaleza y del hombre. Marx define al hom-

${ }^{11}$ Ramón Gil Novales en su versión castellana del libro de Arendt las ha traducido respectivamente por "labor, trabajo y acción", traducción directa del inglés "Labor, work, action". Sigo la versión francesa de Georges Fradier que me parece más fiel al pensamiento de la autora: trabajo, obra, acción. 
bre como una fuerza productiva, y por el trabajo el hombre obtiene su dominio sobre la tierra y se libera a sí mismo. El menosprecio por el trabajo que se sentía en la Antigüedad se ha convertido en la época moderna en su glorificación. Una tal metamorfosis proviene de una consideración subjetiva del trabajo y no es una metamorfosis del mismo trabajo. Marx descubre que es la principal actividad del hombre, porque está en el origen de la propiedad y de la riqueza, aunque el fruto de esa actividad humana se encuentra alienado. La condición humana aparece así en violencia porque está desposeída de su propia realidad. Conviene pues que aquella actividad que es el trabajo llegue a ser un camino de liberación para el hombre esclavo. Pero Hannah Arendt precisa que esta liberación se produce en el seno de una sociedad de consumidores, que precisamente experimentan en el consumo la libertad de poder disponer de ellos mismos.

Arendt propone un segundo tipo de actividad que corresponde a lo que no es natural dentro de la exigencia humana, a lo artificial, y que queda excluido del repetirse del ciclo vital de la especie. Se trata de la obra. Es una actividad que nos proporciona un mundo de objetos que exceden todas las circunstancias naturales. Por este motivo la condición humana de la obra es la mundanidad. Las obras extraídas de la naturaleza por la mano del "homo faber" se instalan en el mundo con una cierta independencia del hombre que las ha producido. Las cosas que han sido fabricadas por el artesano adquieren una estabilidad que las hace durar más allá de la vida del autor. La obra se convierte en una especie de réplica de la actividad creadora de Dios, ya que el artesano transforma la naturaleza para crear en la obra un nuevo ser. La obra no es como la naturaleza que no se altera por el trabajo, sino que transforma y reifica, creando objetos que no existían. No obstante, la duración de dichas obras es relativa, ya que está sometida al deterioro, a la fragilidad y a la corrupción. La obra deja plasmado en la materia un eidos, una idea que le ha inspirado y que ha guiado la acción del autor. De hecho, el "homo faber" persigue ampliar la duración de la vida humana a través de la fabricación de instrumentos. Por eso, los instrumentos que alivian el trabajo del "animal laborans" los ha hecho el "homo faber". El utensilio prolonga de esta forma la mano humana. Sin embargo, las máquinas tienen una complejidad superior y piden que el hombre se sirva de ellas, pero también que las sirva. En efecto, la automatización de la fabricación ha implicado una separación progresiva entre hombre y mundo natural, hasta el punto que el mundo de las máquinas llega a ser un sustituto del mundo real. La obra acaba rigiéndose por el principio utilitarista de los fines y de los medios $y$, por eso la aparición de la máquina ha pervertido la fabricación del artesano. La finalidad que buscaba en la fabricación de objetos se ha adulterado en un utilitarismo que se guía por otras finalidades, como por ejemplo la obtención de riqueza. Cuando la fabricación ha desembocado en el 
mercado, sus objetos se han degradado en mercancías. A pesar de todo, la obra mantiene aún su estabilidad en el mundo de los objetos artísticos, donde la obra de arte es todavía creación y no mercancía.

Finalmente, la acción es la única actividad que se da entre los hombres sin la mediación de cosas o de materia. Es la actividad más efímera pero al mismo tiempo la más humana, porque crea el espacio de la relación con los demás. De esta manera, la acción corresponde a la condición humana de la pluralidad. Arendt baja al terreno de lo concreto y considera que el hecho es que los hombres y no el Hombre, viven sobre la tierra y habitan en el mundo. El fundamento de la acción se encuentra en la palabra a través de la cual se establece la comunicación entre los humanos y se construyen las relaciones humanas. Podríamos decir que la acción cubre todo el terreno político en el cual el hombre adquiere el reconocimiento de su propia libertad. La acción sería un lujo innecesario, una caprichosa interferencia en las leyes generales de la conducta, si los hombres fueran de manera interminable reproducciones del mismo modelo, la naturaleza o la esencia del cual fuera tan predictible como la naturaleza o la esencia de cualquier cosa. Por eso, la pluralidad es la condición de la acción humana, porque todos somos la misma cosa pero nadie es igual a cualquier otro que haya vivido, viva o vivirá.

Si los humanos no fuéramos diferentes no necesitaríamos ni el discurso ni la acción para entendernos. Pero entonces esta vida sin acción ni discurso no sería en consecuencia una vida humana. La palabra "actuar» proviene de la palabra griega "ariein", es decir, comenzar: lo que significa que con la acción empieza no algo nuevo, sino alguien. Dice San Agustín: Initium ergo ut esset, creatus est homo, ante quem nullus fuit. Que con la acción empieza el hombre quiera decir que podemos esperar de él lo inesperado. Pero la acción va acompañada por el discurso porque en ella se revela el agente, de manera que ante cualquier acción nos acompaña siempre la cuestión que dirigimos al agente: ¿quién eres, tú? Por esta razón, la acción en el interior de la vida del hombre se cumple como un hacerse a sí mismo.

La acción, a diferencia de la producción, nunca es posible en el aislamiento. La acción necesita la presencia de los demás tanto como la producción necesita la presencia del mundo. La distinción entre actuar y hacer ya fue captada por los griegos y latinos, que designaban con dos palabras diferentes: "pratein" $y$ "poiein", y su correspondencia latina, "agere" y "facere". La acción supone, por tanto, una actividad capaz de establecer relaciones con otros agentes, mientras que la producción de la obra supone sólo la actividad de quien se enfrenta solamente con la naturaleza para producir obres permanentes al margen de la acción. Las obras, una vez terminadas, hablan por sí mismas, mientras que la acción necesita 
siempre la interpretación de un narrador. He aquí por qué la acción política va acompañada siempre de un parlamento.

El análisis de Hannah Arendt había señalado que el ideal de la vida activa había culminado en el mundo de la "polis" griega. Los atenienses sobre todo llegaron a discutir en el ágora las maneras de conducir la ciudad de una forma verdaderamente humana y esta democracia incipiente ha inspirado también todas las democracias de nuestro mundo, una vez superados los peligros del totalitarismo. Arendt dirige su crítica a la modernidad para mostrar que este ideal humano basado en el desarrollo de la vida activa, la vida moderna lo ha perdido. En efecto, con la evolución de la vida privada ha llegado el individualismo y la dimensión pública de la vida social ha reculado y se ha introducido el elemento social igualitario, a causa del acceso a la propiedad privada y de la introspección de la conciencia. Por eso, primero el "homo faber" y después el "animal laborans" han reducido toda la actividad humana primero a la obra y luego al trabajo.

En realidad, el hombre moderno, empujado por la preocupación de ganarse la vida, acaba perdiéndola, ya que lo que hace es trabajar para subvenir a sus necesidades, obrar para construir un mundo de objetos, de los cuales los más eminentes son las obras de arte, y actuar en el sentido político para establecer un mundo común basado sobre valores comunes. De las tres posibilidades de la vida activa, la acción es la que ha sido sacrificada. Nuestra época está marcada por una pérdida de lo que es político y por un triunfo de lo que es económico. En consecuencia, la condición del hombre moderno es la de un "homo laborans" que ya no se reconoce en lo que hace, y no la del animal político, según la definición de Aristóteles, que se construía a si mismo construyendo la ciudad. Esta inmersión en la economía es, para Arendt, una amenaza para el futuro del hombre. Ni el cuidado del "homo faber" en la producción de los objetos ha sido ahorrado en su aspecto humano, ya que la producción se ha hecho seriada en una sociedad económica que lo destina todo al consumo.

\subsection{Recapitulación: educación de la acción}

El análisis de Hannah Arendt ha mostrado la importancia de la vida activa y su orden para la correcta construcción de la condición humana y al mismo tiempo ha denunciado sus peligros. El reto de nuestra sociedad económica sólo podrá ser conjurado a partir de una educación que tenga en cuenta la centralidad de la acción en la vida del hombre y el respeto de este esquema jerárquico de la vida activa. Ante el desafío de una situación que es una amenaza para el hombre, la 
tarea educativa se ha de confrontar con las condiciones adversas de la vida humana en nuestro tiempo y conseguir guiar la actividad de los educandos.

Hay que empezar por reconocer la cualidad de la acción como elemento primordial de la vida. La vida es acción, espontaneidad, perfeccionamiento. En consecuencia la educación ha de reconocer esta realidad para conducirla, no para obstaculizarla o frenarla. Este es el reconocimiento del verdadero carácter activo de toda educación que considera en el educando un sujeto agente y no un sujeto paciente de una imposición extraña. Conducir este empuje y hacer que se potencie evitando su dispersión es el quehacer de un buen pedagogo. Los estímulos, los motivos y las sugestiones han de hacer avanzar aquel impulso de una manera positiva. La orientación la irá descubriendo el mismo educando.

El primer riesgo al cual hay que estar atento es que la acción no se desborde sin sentido y, por tanto, sin eficacia. Eso sucede cuando la acción brota sin control y sin reflexión, como si fuese un actuar sin agente, la acción por la acción, pero sin un sujeto que responda de ella. Nos encontramos ante el activismo en el que la acción desbordada deja de ser una acción humana. La acción ha de ser siempre el fruto de un sujeto que la puede conjugar en todas las personas de la gramática, excepto en el impersonal. Hay que tener pues cuidado para que la acción sea del todo personalizada provocando siempre que la conciencia del sujeto se la apropie y pueda decir: "esta es mi acción».

Una pedagogía personalista, que tiene como objetivo la emergencia de la persona humana, no puede comportase según el principio del carpe diem, de la obtención inmediata de una felicidad a costa de los demás. El principio hedonista, que busca únicamente la comodidad y el bienestar individuales, no es ni realista-ya que la vida comporta muchas situaciones adversas- ni productivo -porque no aporta un aumento de vida ni para sí ni para los demás-. La actividad que conduce a ello está sin duda mutilada y no da fruto ninguno. La expresión que habíamos oído: «tienes que llegar a ser un hombre de provecho» es, en principio, ambigua, ya que no se determina en favor de quién es el provecho que se espera obtener. La expresión no excluye una interpretación utilitarista que valora más los resultados que el propio ser de la persona. Hay que guiarse en definitiva por unos principios que reconozcan la acción plural y respetuosa de los hombres, de manera que puedan convertirse en caminos para las generaciones futuras.

Escuela activallamábamos a aquel tipo de institución que se centraba en la actividad del alumno, considerado como agente principal del proceso educativo. A través de su actividad orientada iba construyendo sus conocimientos y su personalidad. 
Pero era bueno también que en su progreso se le dejara equivocarse, para que aprendiera a corregir el objetivo o la orientación. Este aprendizaje, lento al principio, se hacía cada vez más sólido y seguro, más que el de quien transcurría por caminos trillados. Siguiendo el análisis de Arendt nos podríamos preguntar qué tipo de actividad habría que fomentar. El trabajo monótono y repetitivo, la obra creadora y personal o la acción social y personalizadora. Posiblemente en la actividad educativa intervienen los tres tipos de actividad, pero solamente se acredita su valor si culminan en la acción. La actividad humana no ha de quedar limitada al trabajo, ni a la producción, sino que tiene que culminar en acción, a fin de que el alumno pueda acabar verbalizando lo que ha hecho conjuntamente con otros. Las escuelas ideológicas harán trabajar a los alumnos con actividades miméticas, las escuelas humanísticas procurarán que los alumnos produzcan obras singulares y artísticas, pero sólo las escuelas personalistas culminarán la tarea educativa en un proyecto colectivo que ponga en marcha una acción.

La emergencia de la persona pasa, pues, por el hilo conductor de la vida y éste no es un camino fácil, sin estorbos, sino que presenta dificultades que hay que resolver. Hace falta que la persona se confronte con los problemas y que estos no se conviertan en un callejón sin salida, sino que sirvan de aguijón para continuar creciendo. Hace falta que el alumno que crece se confronte con los problemas, se cuestione, se contraste con la vida de los demás para poder medir la realidad de su propia vida. Ha de acabar aceptándose, a pesar de todo, es decir reconociendo que él mismo es un sujeto inacabado e imperfecto, sin que eso le impida caminar. Así aprenderá a ser crítico, no desde un perfeccionismo que mira a los demás des arriba, sino desde un realismo que le hace apreciar los límites de las coses y de sí mismo. Y todo ello desde su propia vida sin que haya de recorrer a opiniones prestadas y poco vividas. Triunfar en una vida así es el camino de la madurez.

\section{La alteridad}

Nuestra consideración de la persona sería incompleta sin el trabajo que impone la alteridad. La condición humana no nos empuja a vivir una existencia aislada como la de Robinson Crusoe, sino que es constitutivamente una existencia compartida. La pluralidad que se junta bajo el concepto universal de la filosofía esencialista no es otra cosa que una multiplicidad numérica que se une indistintamente como individuos de una misma naturaleza, pero si consideramos al hombre a partir de la existencia, después de reclamar su individualidad, como hizo Kierkegaard, hemos de reconocer que eso desemboca en el reconocimiento de una existencia 
compartida. Vivimos con los demás, es decir, convivimos. La filosofía clásica ha menospreciado habitualmente la reflexión sobre la alteridad. El paso del idealismo alemán más bien facilitó la supresión del otro en aras de la identidad de un falso nosotros, el todo, infinito de la idea o de la razón. Y eso desembocó fatalmente en la aparición de sistemas totalitarios que negaban el valor de las personas y las sometían a la totalidad de un estado, de un partido o de una idea. Conocemos suficientemente los horrores que trajo una realización de esta calaña.

Siguiendo el hilo del pensamiento fenomenológico eso nos ha permitido recuperar el sentido de la conciencia y el valor de la existencia. Comprender el alcance de una existencia inmersa en el tiempo y proyectada a su propia realización nos ha descubierto la vida humana bien abocada a la angustia de lo imposible, bien abierta a la esperanza del misterio. El descubrimiento de los demás aparece entonces como un elemento que acompaña la propia existencia, como un existir compartido. En este punto quisiera alejarme de una consideración que domestica al otro hasta el punto de asimilarlo a las estructuras de la propia identidad, porque en esta situación la radicalidad que representa la aparición del otro desaparece. Prefiero abrir mi pensamiento a las filosofías de la relación para descubrir que la realización de la persona comienza por la llamada del otro. En efecto, nosotros no vivimos espontáneamente en un universo de sustancias, sino de relaciones, y es desde la relación como toma sentido la realidad de la persona. De entrada, hemos de reconocer que una relación no es posible sin que haya una separación original. Rosenzweig habla de esta situación de separación radical de tres sustancias originales: el mundo, Dios y el hombre para poder explicar el inicio de las relaciones entre ellas: creación, revelación y redención. Con el inicio de las relaciones la triple realidad hace su entrada en el tiempo. La figura que forman los dos triángulos superpuestos, el de las sustancias y el de las relaciones, forma una estrella, la estrella que da nombre a la obra mayor de Rosenzweig, La estrella de la Redención. ${ }^{12}$

Buber simplifica este pensamiento mostrándonos que

el Yo del hombre es doble también, ya que el yo de la pareja verbal Yo-Tú es diferente que el de la pareja verbal Yo-Eso... Cuando el hombre dice Yo quiere decir lo uno o lo otro. ${ }^{13}$

${ }^{12}$ Moses, S. (1997) Système et Révélation, op. cit., p. 60.

${ }^{13}$ Buber, M. (1923) Yo y Tú, Buenos Aires, Nueva Visión, p. 20. 
Dos filosofías distintas encuentran su origen en una $u$ otra de esas primeras palabras, de manera que decir Yo ya es iniciar el pensamiento de la una o la otra: la primera se abre al encuentro, y por tanto, a un mundo personal, mientras que la segunda se reduce al conocimiento de las cosas e inaugura un pensamiento objetivo. Es cierto que se puede pasar de la una a la otra, pero el peligro de caer en el mundo objetivo nos conduce a reducir cualquier relación a una objetivación del hombre. Buber nos dice otra cosa importante: que Yo me convierto en yo diciendo tú. Toda vida verdadera es un encuentro. ${ }^{14}$ En realidad, el primero que introdujo en la filosofía la relación yo-tú como intrínseca al hombre fue Ludwig Feuerbach en su La esencia del cristianismo, cuando avanza que no podemos decir Yo sin decir Tú, ni decir Tú sin decir Yo. Pero, además, Buber explica que en la relación entre personas existe una reciprocidad, es decir que los papeles a jugar son reversibles y nos hacen reconocer iguales en el intercambio. En este contraste con las demás personas aparece el sujeto, en la medida en que se reconoce diferente de los otros seres separados de él, y se convierte en persona en el momento en que entra en relación con ellos. Así comienza también el mundo social cuando las personas que han entrado en relación son capaces de reconocerse en comunión las unas con las otras formando la nueva entidad personal del "nosotros". Sin embargo, Buber nos advierte también que bajo el nombre de sociedad se confunden dos realidades diferentes: la comunidad, fundada en la verdadera relación y la asociación de las individualidades agrupadas sin una verdadera relación entre ellas. El filósofo denuncia que esta ausencia de relación caracteriza la humanidad moderna.

Rosenzweig ${ }^{15}$ nos recuerda que no es posible la primera persona sin la presencia, aunque sea implícita, de la segunda persona. ${ }^{16}$ Eso implica que la vida del hombre queda ya enlazada en la pluralidad, pero no perdida en la masa, ya que cada uno es un ser único y el nombre propio que lleva significa precisamente que existe de una manera única. Podríamos decir que la realización de la persona pasa per la llamada del otro, por la experiencia del otro. Yo no puedo llevar una existencia aislada porque la ignorancia del otro me impediría la verdadera experiencia que me abre a la realidad. Pero, para que la relación se efectúe, hace falta la obertura del sujeto que se ofrece y a aquella obertura tiene que corresponder también la del sujeto que acepta. En consecuencia, entrar en la relación implica un gesto de la

14 Ídem, p. 30.

15 Walter Kasper escribió sobre el pensamiento de tres filósofos dialógicos -Buber, Rosenzweig y Ebner- bajo el título Der Andere (El otro).

${ }^{16}$ Moses, S. Système et Révélation, op. cit., p. 95. 
voluntad por el cual pasamos del egoísmo al intercambio. En realidad se trata de una verdadera conversión, hecha a través de un acto de confianza y de aceptación de la alteridad. Permanecer cerrado en sí mismo es enfermizo, como lo manifiesta el autismo, que es el caso límite de la enfermedad que se caracteriza por el cierre y la falta de relación. En realidad limitamos nuestra humanidad cuando nos negamos a este paso hacia el otro y permanecemos cerrados en nuestro interior. Entrar en la relación exige una aproximación que pasa por la sensibilidad y la vulnerabilidad hasta la interpelación del otro. Una caricia en la piel que nos hace sentir la verdadera proximidad del otro, la vulnerabilidad que nos hace compadecer al otro en su sufrimiento a través de un dolor inducido en la propia carne y la interpelación que nos permite ser tocados por la palabra del otro. Estas son las actitudes que nos preparan al encuentro con el otro.

Ahora bien, según algunos filósofos existencialistas, la existencia de los otros se presenta como una amenaza para la propia existencia. Sartre ve la mirada de los otros, como los ojos petrificantes de Medusa, que nos atenaza y nos reduce a nuestra propia imposibilidad. Los otros son el infierno ya que me reducen a objeto e impiden mi existencia. En la medida en que intenten captarme me quitan la libertad, que es mi esencia. La filosofía existencialista de Sartre contrasta con la de la mayoría de autores personalistas, ya que allá donde él sólo ve una pasión inútil y se siente condenado a una libertad absurda, los pensadores personalistas descubren en el rostro del otro el origen de un sentido que nos abre al don y al amor. El otro no es límite sino puerta y obertura. Descubrir que cada hombre es diferente y que es portador de un tesoro único en el mundo nos ha conducir a tenerle respeto. Este respeto ha de preceder a su identificación, es decir-como piensa Lévinas- la ética ha de preceder la ontología. ${ }^{17}$ La ética es la filosofía primera y no la ontología, he aquí lo que Lévinas quiere comunicar, presentando un pensamiento que no resulta ajeno al de sus predecesores, Buber y Rosenzweig. Que el respeto al otro es anterior a su definición, y también que la obertura a lo que nos supera es más verdadera que la percepción de nuestro conocimiento.

El pensamiento de Lévinas se desarrolla en su obra Totalidad e Infinito como una oposición entre la filosofía occidental, la que va de Jonia a Jena, y la filosofía judía. La primera busca reunirlo todo alrededor de un concepto del ser que es englobante y asimilador, mientras que la segunda permanece abierta ante la diversidad, ante el pluralismo que hay que respetar. Lévinas descubre en el rostro del otro la experiencia original de la que brota mi vivir humano. El otro se convierte en el origen

17 Este es el tema del artículo famoso con el que Lévinas manifestó la novedad de su pensamiento: «Éthique comme philosophie prémière» aparecido en la Revue de Métaphysique et Morale en 1982. 
de la relación y de la vida y, a la vez, en la comprensión de que mi vivir ha de ser ético. Decía Buber que los hombres son desiguales por naturaleza y esta no busca hacerlos iguales. ${ }^{18}$ Esta desigualdad se traduce también en la diversidad de circunstancias que crean nuestras diferencias y que son el origen de nuestras heridas. Fiel a esta filosofía, el pensamiento de Lévinas nos ofrece en el concepto de rostro la experiencia única del hombre desvalido. Se trata del extranjero, el huérfano o la viuda que eran presentados en el Antiguo Testamento como prototipos del ser humano que no tiene nada, fuera de su carácter marginal. No se trata de un rostro cualquiera, sino de aquel que me habla desde la necesidad y la angustia y que me pide que no lo deje caer. Para Lévinas, ante esta experiencia única comienza todo el sentido. Antes de describir cualquier esencia se impone una respuesta, se impone establecer con aquel rostro una relación que lo acoja y lo salve. La ética encuentra en este punto su origen y su primacía delante de cualquier ontología. A partir de esta nueva revolución copernicana se impone otro estilo de pensar. Rosenzweig ya había hablado del «nuevo pensamiento», no el pensamiento de un yo aislado y narcisista, sino el pensamiento de alguien que se siente interpelado desde una llamada exterior. Este nuevo sujeto es el que Ricoeur llama sujeto convocado. Lo que cimienta la subjetividad es la pregunta que Dios dirigió a Caín después de haber matado a Abel: ¿¿ónde estás? ¿ Qué has hecho de tu hermano? No se trata de una pregunta sino de una llamada a la responsabilidad. ${ }^{19}$

Así pues, este sujeto convocado queda instalado en la relación ética, que es una relación de respeto hacia el otro. Ello implica un giro en la propia conciencia que permite descubrir que el centre del mundo real no se encuentra situado en el ego -ver el imperialismo de los egocentrismos que hemos heredado desde Descartes- sino en el otro, que merece todo mi respeto, mi estima y mi protección. La existencia es vivida, pues, desde la relación que, entendida como un vínculo con el otro, constituye la esencia misma de la religión. Estar vinculado a otro es reconocer nuestra dependencia respecto de él, que equivale a tener cuidado de él. Yo me debo a él, me debo a los demás y no puedo dejar de sostenerlos.

Un tal descentramiento del sujeto hacia el otro está tipificado en la figura del maestro, especialmente del maestro que me dice lo que hay que hacer, ya que sin él no lo sabría, ni habrían nacido en mí las actitudes éticas. Donde San Agustín hablaba de la existencia de un maestro interior, Lévinas nos hace reconocer sobre

${ }^{18}$ Buber, M. (1948) Le chemin de l'homme, Mónaco, Du Rocher, p. 20.

${ }^{19}$ MOSES, S., Système et révélation, op. cit., p. 109. 
todo la existencia de un maestro exterior. ${ }^{20} \mathrm{El}$ rostro del otro es quien nos exige la justicia y nos enseña la verdad. Pero, ¿̇qué nos enseña aquel maestro y a qué nos obliga? Nos enseña la justicia y lo que dice se formula con un imperativo: «No matarás». Ante el rostro que me suplica, no puedo esquivarlo ni me puedo escapar de él porque estoy obligado a responder y mi respuesta ha de ser una respuesta ética. Justamente porque no puedo deshacerme de él siento el peso de la responsabilidad que me obliga a respetarlo. ¿Cómo podría deshacerme de él sin cometer un homicidio? Tendría que borrarlo de mi conciencia, que aniquilarlo, mientras su voz no dejaría de clamar: «No me matarás». Por este motivo quedo obligado al respeto.

El análisis de la relación con el otro que hace Lévinas podría quedar encerrado en una relación a dos, como la que ya se daría entre un yo y un tú, formando un núcleo cerrado y otra vez solitario. Lévinas muestra que la aparición del tercero rompe el peligro de aislarse y abre la relación a la implantación de la justicia. En la Ética a Nicómaco ya se percibe esta progresión desde la relación de amistad a la obertura a la justicia. En consecuencia gracias a la vía de la alteridad el sujeto se abre al respeto de los demás y amplía la relación ética hasta convertirla en imperativo universal. Lo hace más a través del descubrimiento del tercero reproducible hasta el infinito que per la vía de la abstracción. La ética aparece siempre con un trasfondo concreto, nunca abstracto. Por esta vía el sujeto descubre el colectivo del que forma parte y llega a ensancharlo hasta el pluralismo que es el concepto que proporciona la verdadera dimensión de la humanidad. ${ }^{21}$ Por esta vía pues -y no por la de la abstracción- Lévinas accede a una universalidad que no tiene nada que ver con la totalidad conceptual del espíritu hegeliano. Su pluralidad conserva la realidad de los singulares vivientes y diversos, mientras que en la totalidad hegeliana el singular se pierde, porque queda englobado y superado por el concepto. Una globalización comunitaria no borra los singulares en su seno, sino que sólo puede existir respetando a los individuos que la forman.

Lévinas ha expresado su pensamiento sobre todo en dos obras mayores: Totalidade Infinito, que fue su tesis de estado y De otro modo que ser, que fue escrita después de la época de influencia estructuralista y en la que su pensamiento responde a los retos de las doctrinas de su tiempo. Su pensamiento se desarrolla progresando en un estilo más penetrante, fiel a las ideas expresadas anteriormente. Su lenguaje

\footnotetext{
${ }^{20}$ Lévinas juega con el doble sentido de la palabra francesa "maître», que significa tanto maestro como patrón que manda.

${ }^{21}$ El concepto de pluralismo para Lévinas es un universal ético y no de un universal abstracto.
} 
se hace más hiperbólico y sus conceptos adoptan unos contenidos excesivos que confirman el pensamiento que ya había expresado en la vía del descubrimiento del rostro. Sobre todo porque el rostro nos hace abandonar el terreno del pensamiento abstracto, que resulta empobrecedor, y nos introduce en un diálogo vivo, donde la palabra no se divierte con las esencias sino que se dirige a las personas. En realidad, establecerse en este pensamiento exige una verdadera conversión del espíritu, un auténtico giro copernicano del sujeto.

Pero la humanidad menos ebria y más lúcida de nuestro tiempo... no tiene ninguna otra sombra en su claridad, ni en su reposo otra inquietud u otro insomnio que los que le llegan de la miseria de los otros, donde el insomnio consiste en la imposibilidad absoluta de escaparse o de distraerse. ${ }^{22}$

El pensamiento excesivo de Lévinas nos transportará a una nueva figura de sujeto, que es más que conciencia, más que un yo y más que un ser en el mundo. La sensibilidad, la proximidad, la inmediatez y la inquietud no están constituidas por la apercepción de un yo transcendental que contemplara la unión de la conciencia a un cuerpo. La encarnación no es el fruto de una operación transcendental de un sujeto que se sitúa en el centro del mundo que él mismo se representa, sino que lo sensible, la maternidad, la vulnerabilidad y la afectación se anudan en una intriga más amplia que la apercepción de sí mismo, intriga que me ata a los demás antes de atarme a mi cuerpo. ${ }^{23}$ Lévinas realiza la descripción de un nuevo sujeto constituido éticamente desde el otro. Por eso la humanidad propiamente dicha no debe ser entendida como conciencia-es decir, como la identidad de un yo dotado de saberes y de poderes- ya que mi próiimo me corresponde antes de cualquier encargo y antes de cualquier compromiso. No me corresponde porque pertenezca a mi especie, ya que el prójimo justamente es otro. Mi comunidad con él comienza en la obligación que tengo respecto de él, teniendo en cuenta que es mí hermano. ${ }^{24}$ La responsabilidad por el otro es previa a todo conocimiento, porque se trata de una anarquía ${ }^{25}$ que se da en una situación ética más allá de toda ontología y de cualquier lógica.

\footnotetext{
22 LÉVINAS, E. (1974) Autrement qu'être, La Haya, M. Nijhoff, p. 148 (hay traducción castellana, Salamanca 1995, Sígueme).

${ }^{23}$ LÉVINAS, E. ídem, p. 123.

${ }^{24}$ LÉVINAS, E. ídem, p. 138.

${ }^{25}$ La etimología de la palabra anarquía supone la ausencia de principio. Eso quiere decir que nada comienza con nuestra intervención porque nuestra conciencia se instala en una situación que ya ha comenzado y el principio de la cual no se encuentra a nuestro alcance.
} 
La conciencia, pues, -saber de sí por sí-no agota la noción de subjetividad, que se basa sobre una identidad que llamamos Yo. La identidad de sí mismo no consiste en una realidad individualizada gracias a su diferencia específica o gracias a una coyuntura natural o histórica, sino en la unicidad del que está asignado. El sí mismo se hipostasia, pues, de otra manera: está vinculado y nada puede desvincularlo de su responsabilidad por los demás. ${ }^{26}$

El sí mismo es "sub-jectum", es decir que se encuentra bajo el peso del mundo entero, responsable de todo y de todos, como dice Dostoiewskj en Los hermanos Karamazov. No se trata de que el mundo sea lo abarca mi mirada en la unidad de su apercepción, sino lo que de todas partes reclama mi responsabilidad y lo que me acusa. El sujeto, pues, es declinado en acusativo, como una asignación a responder sin escapatoria y que asigna al sí como a sí mismo. Lévinas presenta esta progresión hiperbólica de los conceptos que describen al sujeto como obsesión, acusación y persecución. Y descubre aún otra figura para designar esta subjetividad, con la imagen del paso del otro dentro del sí mismo, como la inspiración, que es signo de vida del cuerpo viviente. Esta inspiración interroga la posición afirmativa de sí mismo, de cualquier egoísmo que pretende siempre recuperar su identidad. Entonces, la subjetividad del sujeto consiste en la puesta en cuestión por el otro, puesta en cuestión que desemboca en la sustitución de sí mismo por el otro. ${ }^{27}$ Ser Yo consiste entonces en quedar sustituido por el otro y, paradoxalmente, en esta sustitución es donde yo llego a ser yo mismo y no otro. ${ }^{28}$ El sujeto alcanza de esta manera la incómoda situación del rehén, que carga sobre sí mismo la responsabilidad por el otro hasta el extremo de ser-lo todo para él. Ser sí mismo consiste, pues, en des-interesarse, cargando la miseria y el fallo del otro e incluso toda la responsabilidad que el otro pudiera tener de mí. Ser sí mismo es la condición de rehén, tener un grado de responsabilidad más, la responsabilidad por la responsabilidad del otro. ${ }^{29}$ Que la subjetividad sea definida por la noción de rehén trastorna la posición en que aparecía el Yo, como el principio o el final de la filosofía. El sujeto que reposaba en sí mismo queda descabalgado de su lugar central por una acusación sin palabras. El pensamiento de Lévinas aparece

\footnotetext{
${ }^{26}$ LÉVINAS, E., op. cit., pp. 166-167.

${ }^{27}$ La palabra sustitución proviene del latín sub-stare, que significa estar debajo. Curiosamente la palabra sustancia también tiene la misma etimología.

${ }^{28}$ LÉVINAS, E., op. cit., p. 201.

${ }^{29}$ LÉVINAS, E., ídem, pp. 184-185.
} 
aquí con toda su radicalidad, proponiendo la prioridad de la responsabilidad en relación con la libertad, la prioridad de la ética en relación con la ontología. En este punto encuentra un precedente en la intuición platónica cuando encabeza con la idea de Bien toda la jerarquía de las ideas: que el Bien se coloque antes que el ser, significa la necesidad del Bien de escogerme primero antes de que yo pueda escogerlo o acoger su elección.

Podríamos acabar retornando al pensamiento de Rosenzweig, que dirige una mirada escatológica sobre la relación del hombre con el mundo y con los demás, ya que en vez de considerar esas realidades de una manera intemporal, introduce en ellas la dimensión del tiempo para vehicular las tres relaciones fundamentales. Rosenzweig se opone en ello al marco de la filosofía clásica que se extiende desde Jonia hasta Jena, es decir de los presocráticos griegos hasta la Fenomenología del Espíritu de Hegel, que es una filosofía hecha de abstracciones, aislada y olvidadiza de la relación con el otro. Al contrario, Rosenzweig ha reconocido que nuestra relación con el mundo no es originariamente una relación de conocimiento sino una relación moral, ya que la alteridad radical del mundo aparece a través del prójimo. El hombre sale pues de los límites de su egoísmo del conocimiento, que asimila todo lo que encuentra, en el momento de entrar en relación con Dios y con el mundo. La relación del hombre con Dios se realiza a través de la escucha de la palabra que revela su amor, y la relación con el mundo culmina la obra de la Redención, momento en que la palabra recibida penetra en el mundo. A la salida que el hombre hace de sí mismo Rosenzweig la llama amor. La palabra revelada se dirige al mundo a través del colectivo humano que por la liturgia del canto coral se manifiesta por naturaleza como canto de la comunidad. Así pues, tanto la filosofía de Rosenzweig como la de Lévinas culminan en una escatología final que incorpora el tiempo a la intriga humana. No se trata de un pensamiento cerrado desde un principio humano, sino de un pensamiento abierto que ve desde más acá de nuestro nacimiento, ya que la vida no ha comenzado con nosotros, y va más allá de toda finalidad controlada por nuestra voluntad hacia un futuro que no nos pertenece. Lo que Rosenzweig se ha atrevido a bautizar como nuevo pensamiento es un pensamiento que admite como naturales los conceptos de Creación, Revelación y Redención ya que explican desde el otro el tiempo de la existencia.

Esta reflexión sobre la alteridad nos conduce a extraer consecuencias educativas. Aunque el proceso de la educación se opere de una manera individual, no hay duda de que el carácter social de la vida humana no es un hecho accidental, sino que constituye íntimamente la esencia de la persona. La época de los preceptores particulares que tenían cuidado de la educación de uno o dos jóvenes de las familias aristocráticas, ya se terminó. Hoy, la educación se produce mayoritariamente 
en instituciones sociales, tanto de carácter escolar como en la vida del ocio. Es un hecho que manifiesta que el carácter social de la persona se desarrolla desde el principio en la vida de grupo. El proceso educativo comienza en la vida familiar, en la que el niño adquiere los primeros conocimientos y forma los primeros hábitos. Por eso la estructura familiar permite establecer una base educativa más o menos exitosa según lo haya sido la estabilidad de sus relaciones. Más tarde, el paso de la familia a la institución escolar no se hace sin traumatismos en la vida del niño, que tiene que adaptarse a una nueva situación. La estructura escolar propone una nueva situación social que influirá también poderosamente en el progreso educativo de cada niño, ya que en el seno del grupo cada niño aprende a cooperar.

El mayor riesgo que corren los niños en nuestro tiempo es aislarse: huir de la vida de grupo hacia un universo más cómodo, en el que aparentemente no hay oposición, que es el universo de la propia intimidad. Los temperamentos más retraídos solían exhibir siempre esta tendencia, pero desgraciadamente hoy día el problema se ha generalizado y son una multitud los que se refugian en mundos imaginarios, que no coinciden con la vida real. La vida de grupo exige un esfuerzo y la aceptación de unas relaciones acaso difíciles. Por tanto, huir hacia un mundo abstracto - inhibirse de las relaciones sociales, resulta para algunos una solución menos dolorosa. Sin embargo, esta huida pone de manifiesto un carácter más bien débil o enfermizo que tiene dificultades para inserirse en el medio social. Actualmente, esta huida se ve facilitada por la generalización de mundos virtuales que ofrece la tecnología digital. La aceptación del mundo real resulta con eso algo más difícil. Ahora bien, no podemos valorar aquella tecnología de una manera absolutamente negativa, ya que también gracias a ella podemos ensanchar las relaciones con el uso de las redes sociales que permiten comunicaciones más amplias, aunque acaso poco profundas.

La dificultad que acabamos de presentar se puede ejemplificar con las alteridades anómalas que se crean en la vida de los niños. Podríamos citar dos: la alteridad de la mascota y la alteridad del robot. La mascota, que se puede concretar en un animal en quien se proyectan los caracteres de una relación personal, sin que se produzca una correspondencia del mismo nivel, ya que la respuesta del animal siempre será de una cualidad inferior a la respuesta de la persona. Ciertamente, hay personas que encuentran positivo compartir la vida doméstica con algunos animales de compañía porque ayudan a fomentar una afectividad equilibrada, pero esta convivencia podría convertirse en contraproducente si se pretendiera que la relación con el animal supliera la relación que tendría que despertar otra persona. Por otro lado, los avances técnicos hacen aparecer unos "humanoides" que interactúan con la vida humana facilitando algunos trabajos y ahorrando energía 
en la actividad de los humanos. Se trata de los robots fabricados por el ingenio humano. Han llegado a imaginarlos como un androide tomando la apariencia de una figura humana e imitando con un éxito reconocido las maneras y los hábitos de los humanos. Sin duda, la máquina puede facilitar enormemente la vida humana ahorrándole muchas actividades repetitivas, resolviendo cantidad de problemas y liberando un tiempo que puede dedicar a otros asuntos. La existencia del robot plantea sin embargo problemas de competencia. Se ha llegado a pensar en un robot que pueda emular la vida humana hasta tal extremo que pudiera confundirse con una persona. La literatura y el cine de ficción han simulado situaciones posibles y problemáticas. Hemos de preguntarnos qué es un robot y tomar conciencia de que se trata de una máquina que funciona y que opera de acuerdo con un programa que se le ha dado previamente. Un robot sólo dispone de una autonomía relativa y únicamente puede decidir a partir de las variables de los problemas que se le han programado. Pero, jes eso suficiente para identificarlo con una persona? ¿Podría substituir, por ejemplo, un maestro? He aquí un punto que considero crucial y que me permite iniciar un tema que, a mi parecer, reviste una gran importancia.

En efecto, ¿qqué valoración hacemos de la figura del maestro? Una educación sin relación con la persona de un maestro, ¿̇podría transmitir valores susceptibles de ser vividos? En los tiempos que corren y en nuestro entorno social en el que los conocimientos se han generalizado y la información nos llega de todas partes por vía digital, parece que la figura del maestro pueda ser considerada como superflua. Y, sin embargo, el papel del maestro es esencial y hay que reivindicarlo. La máquina que nos ofrece conocimientos no puede substituir al maestro, aunque éste no dispusiera de tanta erudición ni de respuestas precisas como las que nos puedan llegar por la red digital. La figura del maestro humaniza la acción educativa, porque más allá de la tecnología, establece con el alumno una relación personal que es básica para el progreso. Sin esta relación quedaríamos frustrados en nuestro desarrollo como personas. En primer lugar, porque el maestro ofrece un modelo y testifica sobre unos valores y unas vivencias susceptibles de ser imitados. En segundo lugar, porque la verdadera relación con el maestro es una relación que humaniza, tejida con el calor de una afectividad positiva. Justamente esta afectividad es la que fomenta el crecimiento de la vida del alumno y la enriquece con los descubrimientos que va encontrando en aquella relación. Ni que decir tiene que si una relación no es positiva y la afectividad es nula, el crecimiento del alumno podrá resentirse. Al maestro no hay que evaluarlo primordialmente por la erudición que posea -tal vez un programa informático tenga más cantidad de conocimientos, más memoria y más precisión- sino porque sus conocimientos están envueltos por la vivencia que los hace humanos. A través del maestro el alumno puede llegar a adquirir una visión del mundo, a través de la máquina no. En 
consecuencia, la relación con el maestro resulta ser un acompañamiento valioso para la vida del alumno.

La verdadera educación humana se produce en el interior del grupo. Es posible aislarse o rechazar la interacción, pero esta actitud anómala no evitará la inmersión en una red de relaciones sociales que provienen de los otros. Aceptar la figura del maestro es aceptar la alteridad, pero en el grupo aparecen también las relaciones con los compañeros que forman el grupo y que influyen continuamente en la vivencia del alumno. Además de las actividades individualizadas, el grupo propone una serie de tareas que son comunes y que introducen al alumno en el trabajo de equipo. Saber colaborar, es decir, aportar el propio esfuerzo a una tarea común y saber cooperar, o sea, implicarse en la concepción y en la realización de un proyecto, son actitudes que las situaciones de la vida de grupo proponen a la acción de cada alumno. La vida de grupo aparece a través de estas situaciones que en la medida que tienen éxito, consiguen la integración del alumno y su socialización. Aprender a convivir con los demás, a compartir acciones y experiencias y a entrar en relaciones constructivas plenas de creatividad. Así es como cada persona llega a descubrir el valor de la vida compartida, y a través de este trabajo en grupo aparece también la necesidad de considerar la persona del otro. El nacimiento de la afectividad y del respeto está en la base de las actitudes propiamente éticas, que culminan en la amistad y la justicia. Esos valores el alumno tiene que descubrirlos a partir de la relación con los compañeros.

Pero la relación en el grupo no sería completa si no estuviera abierta al descubrimiento de la universalidad. A través de la manifestación del prójimo, de aquel que está cerca, hay que otear el camino a recorrer hacia la búsqueda de lo que queda lejos. De esta manera lo que es lejano en el espacio puede convertirse en próximo por el corazón cuando la totalidad de los hombres aparece formando la gran familia que es la humanidad. Por este motivo, la obertura al otro ha de atravesar el umbral de las relaciones grupales, para introducirse en las realidades sociales y universales. Los espíritus no pueden quedarse cerrados dentro de las fronteras de todo lo que es propio, sino que se deben abrir al conocimiento y al amor de lo que es extranjero. Así pues, hay que hacer nacer en el corazón del pequeño grupo el interés por el mundo global. Sentir que los humanos, alejados en el espacio y el tiempo, pueden convertirse en próximos si los consideramos con el corazón. Este sería el verdadero sentido de la sociedad global, como ideal hacia el que se dirige nuestra humanidad.

Pero no nos hemos de perder en abstracciones, sino que nuestra sensibilidad se ha de dejar llevar siempre por lo concreto. Este sentido universal se convierte en una 
exigencia moral cuando se trata de acoger el compañero disminuido, que no tiene las mismas capacidades, o el compañero extranjero, que llega desde un país lejano, o el compañero de otra clase social. Un tipo de grupo o de escuela, que acepte a todos los niños sin condiciones, podríamos decir que tiene un carácter inclusivo. A partir de la aceptación de este carácter podemos esperar el nacimiento de un mundo más humano, sin exclusiones, ni de sexo, ni de lengua, ni de religión, ni de posición social, ni de capacidades psíquicas, ni de pensamiento. Esta globalización será verdadera, si en lugar de igualar a todos sus miembros de una manera uniforme, se basa en el respeto de todas las diversidades. Esta globalización es creíble si se mantiene abierta a los propios dinamismos que cambian la sociedad y si ausculta los signos de cada momento. Una escuela o un agrupamiento educativo que se refleje en esa sociedad abierta será un marco desde el que se hará comprensible la ética, ya que propone como ideal que preside su vida, el respeto por el ser de cada uno. Los ambientes educativos llegarán así a ser integradores y harán nacer una nueva cultura de la paz. El antiguo ideal de la fraternidad que formaba parte de la divisa de la Revolución francesa y que es la herencia que el espíritu cristiano dejó en el ideal revolucionario, es todavía hoy un programa pendiente de realizar.

\title{
8. La transcendencia
}

Canta Lluís Llach el poema de Kavafis:

\begin{abstract}
Más lejos, tenéis que ir más lejos de los árboles caídos que os aprisionan. Y cuando los hayáis ganado tened bien presente no deteneros. Más lejos, siempre id más lejos, más lejos del presente que ahora os encadena. Y cuando estaréis liberados volved a empezar nuevos pasos. Más lejos, siempre mucho más lejos, más lejos, del mañana que ya se acerca. Y cuando creáis que habéis llegado, sabed encontrar nuevas sendas.
\end{abstract}

Tratar la transcendencia como tema educativo me parece coherente con la misma constitución de la persona humana, ya que entiendo la transcendencia como la superación de los horizontes de nuestra vida cotidiana para ir más allá de lo que somos. Siguiendo el modelo kantiano, que analiza el ser humano a partir de un triple punto de vista: el del conocimiento, el de la voluntad y el del sentimiento. Nuestra realidad está limitada en el conocimiento por los límites de nuestros sentidos, en nuestra voluntad por los límites de nuestros deseos y en nuestro sentimiento por los límites de nuestros afectos. No obstante, nuestro ser está desgarrado por la llamada que viene del Infinito a conocerlo todo, a desear el infinito y a amar sin medida. En esta ruptura se inscribe la verdadera condición humana, a la búsqueda de una tierra ignota que siempre nos queda más allá de lo que somos y más lejos del lugar donde nos encontramos. 
Pero nuestro mundo no se atreve a hablar de transcendencia, porque la soporta como un vacío, como si el proyecto de ir más lejos quedara sin suelo por donde andar, como el fracaso de nuestra existencia. El pensamiento de Heidegger diseña al hombre al hombre como un proyecto fallido porque está abocado a la muerte. Y esta consideración de la existencia nos encierra en un paisaje en el que los caminos no llevan a ninguna parte. Entonces, el espíritu, la historia, la humanidad o Dios se convierten en grandes palabras que no aportan luz y nuestra vida se consume sin esperanzas. Felizmente, hay otros modelos de pensamiento que ofrecen atajos más luminosos, que hacen posible vislumbrar espacios de sentido y de transcendencia en nuestra vida humana.

Partimos de la base de considerar al hombre como espíritu, incluso si eso nos sumerge en un laberinto de dificultades. Así pues, ¿qué es, el espíritu? ¿Cómo podríamos definirlo? Nuestra actitud personalista supone que el sujeto humano tiene capacidad de iniciativa y de creatividad, pero no como un cúmulo de fuerzas justificable por leyes físicas o biológicas. Hemos hablado de una metafísica del quién, distinta da una metafísica del qué, de la persona contrapuesta a la cosa. Creo que es precisamente ese algo distinto lo que llamamos espíritu. Hoy día, la neurociencia se esfuerza por encontrar explicaciones cerebrales a esas actividades que manifiestan una creatividad y una iniciativa de tipo ideológico, artístico o religioso. No entraré a discutir esas dependencias biológicas, sino a valorar sus resultados. El materialismo no consistiría en considerar un mundo constituido a partir de la materia inerte, sino un mundo sin iniciativa ni espontaneidad, incapaz de ser considerado como origen de dinamismos vivos e imprevisibles. En este punto, la afirmación de un espíritu que se limitara a obedecer a unas estructuras impersonales no sería otra cosa que una forma más sutil de materialismo. Podríamos decir que ante un mundo constituido por personas, la concepción de un mundo gobernado por lo neutro, indefinido o inerte habría que designarla como materialismo.

Ante la interpretación materialista del mundo, la interpretación que hace el espíritu se presenta como un mundo abierto, es decir que el hombre considera la realidad de lo que le supera, precisamente porque en sí mismo se sabe marcado de finitud. Como quien está encerrado en su casa, cuando abre la ventana puede contemplar el paisaje y abrirse al mundo. Por este motivo se despierta en el hombre un sentimiento de admiración por lo que le rodea, capaz de abrirlo a la contemplación de la belleza. En efecto, los ideales estéticos que se inscriben en la naturaleza o en las obras de arte reclaman la atención del hombre y su admiración. El orden de la naturaleza y su inmensidad imponen un sentimiento de admiración que place al espíritu, y la belleza que inspiran las obras de arte, las que contemplamos en los 
museos o las que escuchamos en los auditorios, nos introducen en un mundo más ordenado. La sensibilidad para captar la belleza está al alcance de todos, pero si no se tiene cuidado de cultivarla y de darle el espacio y el tiempo necesarios, puede resultar imperceptible para un espíritu romo.

Nuestra sensibilidad se interesa por todo aquello que es humano, pero también por aquello que fascina por su magnitud. Por eso, la admiración que sentía Kant por el cielo estrellado de noche abría su espíritu a la contemplación de esa maravilla sublime. Según Aristóteles, esta admiración era la puerta que abría al hombre a la interrogación filosófica. Decía que, justamente porque los hombres sienten admiración -de "zaumadso"- por eso desean saber. Y desean saberlo todo, zambulléndose en los misterios que los rodean. En efecto, la Filosofía ha avanzado desde entonces hasta ahora en un proceso que pretende no tener término. Este proceso de preguntarlo todo y de investigarlo todo se ha confrontado muchas veces con la idea de un objeto infinito. La obertura del pensamiento humano invita al hombre a correr el riesgo de sumergirlo en aquel mismo infinito y de perderlo en él. Entonces es cuando una cierta mentalidad oceánica nos rodea en un todo que nos supera y en el cual tenemos el peligro de disolvernos. Un todo que no podemos decidir si es siempre luminoso o bien oscuro como la tiniebla de la noche. Es conocida la crítica que Hegel hacía del infinito de Schelling. Según él, estaba falto de racionalidad y, por tanto, en él no se podía distinguir si las vacas eran negras o blancas. En el idealismo alemán, la transcendencia queda tragada de nuevo en una totalidad englobante, que toma un carácter positivo y optimista en la filosofía de Hegel, pero que en el pensamiento de Schopenhaver se vuelve negativa e irreal. Las filosofías o sabidurías orientales, como el budismo o el taoísmo, manifiestan esta actitud.

El mundo del espíritu queda abierto también a la persona del otro, ya que fuera de nosotros mismos no hay solamente la naturaleza, sino también la comunidad humana, con la voz y el grito de los demás que despiertan nuestra solidaridad. Hemos visto ya que el camino de la alteridad es para cada persona un camino de cooperación que la conduce también más allá de ella misma hacia otras personas y otros horizontes. El vehículo que usamos para comunicarnos dentro de esa exterioridad viviente es el lenguaje. Gracias al lenguaje podemos establecer relaciones con las personas próximas, que son comunicativas y productivas. El lenguaje es un sistema de símbolos comunes que permite describir un mundo que nos es común y crear un refugio que nos hace habitable la naturaleza. Se trata del mundo cultural. En efecto, la cultura describe la peculiar manera cómo afrontamos colectivamente el mundo y define una nueva forma de ser que se superpone a nuestro ser natural. 
Este mundo cultural no ha empezado con nosotros, ${ }^{30}$ sino que nos llega de tiempos pretéritos: al nacer, se nos inmerge en una historia que recibimos y se nos instala en un país. La cultura se convierte en una segunda matriz que nos hace nacer a una realidad plenamente humana $y$, gracias a la lengua, anudamos las primeras relaciones que nos vincularán a la historia y a la tierra. Así, nuestra dimensión social se concreta de una manera cultural: nacimiento dentro de una red familiar, inscripción dentro de una identidad nacional, querida y ejercida. A esta realidad de nuestro espíritu la podríamos llamar sujeto convocado porque es un sujeto que no se constituye en primera persona sino que se sabe constituido a partir de la realidad de los demás. Podríamos decir que encuentra en eso un primer indicio de transcendencia. Los elementos culturales que recibimos empiezan por la lengua, pero continúan por las maneras sociales de hacer y de conocer que configuran unas costumbres y enseñan unas técnicas por las cuales quedamos inscritos en un espacio y en un tiempo. Nuestra vida queda implantada en el seno de una comunidad cultural, pero desde esta base, ¿̇cómo accedimos a la universalidad? A través del conocimiento de la ciencia, a partir de la valoración del arte y por la participación en las instituciones sociales y religiosas, nos trasladamos de lo particular a lo universal. Bien cierto que se trata de una universalidad polimorfa, porque cada hombre, dentro de su cultura, tiene un acceso personalizado. Por eso en la pluralidad de lenguas, en la diversidad de las ciencias, ${ }^{31}$ de estilos artísticos o de espiritualidades y religiones, el acceso de unos a los otros supone un trabajo continuo de hermenéutica y un esfuerzo de interpretación. ${ }^{32}$

La obertura del espíritu al misterio del otro aparece claramente en las filosofías dialógicas, en que la voz y el grito del otro hombre despiertan nuestra solidaridad. En la desnudez y el dolor del otro, sobre todo, escuchamos cómo resuena la palabra que nos interpela. Consideramos la palabra no como un sistema de signos sino principalmente como el acto de decir. Es una llamada que se me dirige y que me señala con la obligación de corresponder. ${ }^{33} \mathrm{~A}$ través de la palabra se hace

\footnotetext{
30 Lévinas habla de anarquía (=sin principio) para expresar el carácter no constitutivo del sujeto respecto del mundo.

${ }^{31}$ Hay que advertir sin embargo que la ciencia tiende a ser unitaria.

32 El trabajo hermenéutico podríamos imaginarlo como el dibujo de una elipse, que se construye a partir de dos focos. Se trata como un círculo que no es vicioso, porque nos permiten ir sucesivamente del uno al otro.

${ }^{33}$ Hay que distinguir entre lengua y palabra, entre lo dicho y el decir, la consideración del lenguaje como sincronía o de la palabra como diacronía.
} 
patente una voz exterior que me desvela de mi letargia y me instala en la vida. Es la obertura de la que hablábamos en la primera parte, cuando con Descartes considerábamos la huella del Infinito dejando la idea de Dios en nuestro pensamiento. Lévinas hablaba de un Infinito que atraviesa nuestros sujetos desde más acá de nosotros y que nos conduce también más allá, como el aire que pasa por los pulmones y los regenera, con el ritmo de la inspiración y la expiración. El aire, que es exterior al organismo, lo revitaliza: de la misma manera el sujeto que es cada uno de nosotros queda abierto a un Infinito que lo atraviesa y renueva. Un infinito que es también una alteridad que viene de lejos y que constituye al sujeto aunque que no se deje cautivar por él. Tal infinito que ciertas espiritualidades neutralizan de una manera vaga y lo retienen sin precisar su identidad, la tradición de espiritualidad personalista lo percibe como un impulso que nos transciende y que, dejando su huella, hace que nuestra conciencia se convierta en una conciencia añorada. ${ }^{34}$ Teniendo presente que no estamos instalados en lo neutro, aquel infinito no puede ser una cosa sino que tiene que ser alguien que nos ha permitido darle nombre. Los místicos han experimentado esta obertura a la transcendencia y han escuchado como un balbuceo que les ha dejado un nombre. El Infinito que se presentó a Moisés en la zarza ardiente le dejó la prenda de su identidad.

Desde el balbuceo intentamos nombrar a aquel que nos atraviesa y nos vivifica, y que se constituye como nuestro principal interlocutor. Él es quien nos instala en el ser y no nosotros, que no somos origen de nada. Todo comienza con su llamada, que es una llamada de amor. Lo que sigue, si consentimos en ello, es un diálogo de amor, diálogo que llamamos plegaria. Desde aquel infinito podemos realizar nuestra vida como camino, ya que su paso por nosotros no nos ha trazado un camino virtual sino bien real. De la misma manera que nos ha descubierto nuestro pasado, que se ha realizado sin nosotros, nos muestra también el futuro, que no se hará sin nosotros, y que es también un camino infinito más allá de nosotros mismos. Camino desde el otro y hacia el otro, inacabable, porque su verdadera dimensión es la eternidad.

Con todo, el hombre se enfrenta hoy con unas condiciones sociales que dificultan el acceso al transcendente. En efecto, el hombre vive inmerso en un medio cultural en que la búsqueda de satisfacciones inmediatas parece imponerse y las invitaciones a comportarse de forma hedonista y egocéntrica no encuentran obstáculos. Nuestra sociedad occidental propone los modelos de una vida fácil, marcada por la comodidad y el placer, y predispuesta a evitar las dificultades. Todos corremos

${ }^{34}$ Marion habla de la nostalgia de una conciencia que queda separada de este Infinito, distante de él. 
el riesgo de buscar las respuestas inmediatas a las pulsiones superficiales que sentimos y de conducirnos movidos por emociones más que por convicciones. Resulta fácil entonces vivir una vida distraída, sin tomar conciencia de la profundidad de nuestra existencia. Pero la búsqueda de una respuesta satisfactoria a corto plazo impide echar raíces, vincularnos a unas relaciones estables y, en consecuencia, nos hace vivir en un mundo falto de referentes. De esta manera, el medio social se ha vuelto poco incitante a una vida comprometida y el ambiente se muestra adverso contra cualquier vestigio de lenguaje transcendente. Se ha consolidado un mundo secularizado, desprovisto de grandes proyectos, en el que la apariencia religiosa resulta opaca. Por tanto, hay que oponer una fuerte resistencia a aquellas solicitaciones si no queremos perder de vista todo lo que constituye nuestra propia identidad humana y perdernos por senderos que no conducen a nada.

Al mismo tiempo tenemos que considerar que la situación del hombre en el mundo de hoy está sometida a un número muy elevado de condicionamientos, de dificultades y de situaciones dolorosas, que le impiden refugiarse del todo en un mundo virtual y efímero. Como en la historia del príncipe Gautama Siddhartha, que vivía tranquilo recluido en su palacio, ignorando la vida de los hombres. Sólo después de abandonar su palacio se encuentra con la realidad. De repente descubre el dolor, la vejez y la muerte, y esta experiencia es para él el inicio de su conversión en Buda. De hecho, la experiencia de la muerte de los demás es ya un anuncio de la propia muerte, que resulta determinante para la vida humana. Y este descubrimiento que hizo Buda del mundo real trastornó su vida. Ciertamente, el descubrimiento del hecho de la muerte significa el aterrizaje en un mundo humano, ya que no topamos con abstracciones sino con el hecho decisivo que no podemos soslayar. La muerte resulta verdaderamente determinante ya que sólo podemos o bien aceptarla con fatalidad como un final que no se puede rehuir, o bien entrever la esperanza de un misterio mayor. En este sentido, el hecho de la muerte tiene que abrir nuestro espíritu a vivir el misterio de la vida y nos da la clave para aceptar la experiencia del mal. Si nuestra aceptación de la muerte nos abre a la vida, tendremos que reconocer que la experiencia del mal es sanadora y la negación resulta fecunda. Hay que atravesar la dificultad y probar el problema para que experimentando el dolor no nos volvamos cobardes o insensibles ante el mal de los demás. Hay que asumir el propio sacrificio para comprender el grueso verdadero de la vida y aprender a compartir con los demás nuestra condición más auténtica. Ni que decir tiene que si a alguien se le ahorrado siempre vivir dificultades, la primera que encuentre en su vida se le hará insuperable.

Pero el descubrimiento del mal y del sufrimiento, ¿̇no se contradice con la afirmación de la transcendencia? ¿ ${ }^{N}$ o es precisamente un camino que ha conducido a 
la sospecha y al ateísmo? Ciertamente, uno de los argumentos presentados contra la existencia de Dios es la existencia del mal, el exceso del mal, en palabras de Nabert, sobre todo del mal que afecta a los inocentes. En palabras de Camus, el mal de los inocentes no sólo impide la afirmación de la existencia de Dios, que por definición ha de ser bueno, sino que nos aboca a aceptar que nuestra existencia topa con un mundo absurdo. ${ }^{35} \mathrm{El}$ exceso del mal hace tambalear la confianza de Job, que se subleva contra la realidad de un mal inmerecido. Desde esta situación nos sentimos alejados de aquella claridad ingenua que respiraba la bondad original que inspiraba nuestra vida y nos sentimos legitimados para protestar con todos los que sufren el zarpazo de lo negativo en su vida. Ahora bien, la negatividad por sí sola no habla, nos desanima pero no nos confirma en la nada. Sólo la palabra puede iluminar esta situación y restablecer la confianza. Pero acoger aquella palabra implica un acto de fe que no se puede pedir a todos.

Nuestro mundo secularizado, en la medida en que ha dejado atrás una imagen monolítica de Dios y un dogmatismo teológico indestructible, ha hecho posible la eclosión de una pluralidad de mundos des de los cuales se entrevén muchas posibilidades de acceder a la transcendencia. Por eso descubrimos actualmente una pluralidad de caminos que implican una obertura del espíritu y adoptan formas diversas. La contemplación de la belleza en las obras de arte, la obertura a las fuerzas de la naturaleza, la experiencia del silencio o la interiorización espiritual son caminos que se concretan a veces bajo el nombre de espiritualidades, vividos en pequeños grupos o practicados de una manera muy particular. No hace falta decir que la experiencia de la contemplación y del silencio abre caminos a una humanidad insospechada. En un mundo tan acostumbrado como el nuestro a ofrecer sólo consumo, ruido y diversión, profundizar, el silencio y la conversión son bienvenidos. Así pues, hay que avanzar por una vida interior abierta a la contemplación de la naturaleza, de la belleza y de la interioridad.

En este marco resulta posible replantear la temática de Dios, y no a partir de un punto de vista institucional, ya que la imagen de Dios ha quedado viciada por la corrupción y el poder. Hay que inventar pues una nueva manera de nombrarlo. Para ir más allá de las críticas de los filósofos de la sospecha hemos de abandonar las representaciones de un Dios que infantiliza, que está de parte de los opresores de los pobres y que impone pesadas cargas a las conciencias. De hecho, todas estas representaciones son construcciones humanas que, como recordó Feuerbach,

\footnotetext{
${ }^{35}$ Albert Camus en su novela La peste narra esta situación del mal de los inocentes, describiendo la muerte de un niño de seis años víctima de la enfermedad. Este hecho manifiesta un mundo absurdo en el cual no se puede creer en Dios.
} 
proyectan más las aspiraciones humanas que la realidad de Dios. Precisamente porque son imágenes elaboradas por el hombre tienen un carácter idolátrico y no manifiestan lo que es el Dios vivo. Cuando Nietzsche anuncia por boca del profeta Zaratustra que Dios ha muerto se refiere al Dios moral, al ídolo construido por los hombres. Pero, con la muerte de aquel Dios moral, el advenimiento de otro Dios se hace posible. Hay que ponerse a la espera de una nueva experiencia del Dios que hace vivir, el Dios que se escapa de toda tipificación humana, porque es el absolutamente otro. Como recuerda Jean-Luc Marion, entre este Dios y nosotros se abre una distancia infinita, un abismo que no podemos recorrer. Cualquier intento teológico para hablar sobre él corre el riesgo de convertirse en idolatría. Por eso, la teología negativa ya hablaba del carácter inefable de aquel Dios sin nombre, porque ningún nombre le conviene. Sólo podremos conocer su nombre si El habla y nos lo revela. Lévinas ha intentado hablar de él usando el término de lleidad con el que quiere expresar la característica de un Dios que viene a la ldea, pero que no acaba de tomar forma en nosotros, porque es esquivo a nuestra capacidad de captarlo. Marion distingue entre las posibles denominaciones de Dios: llama «dios» al ídolo confeccionado por los hombres y, por tanto, un dios no verdadero. Dios ha de estar separado de nosotros por una distancia que no podemos recorrer y escondido a nuestra mirada. Marion piensa que sólo podemos nombrar a Dios si Él nos da su nombre y recorre aquella distancia infinita hacia nosotros. Entonces su imagen no será un ídolo que nosotros nos construimos, sino el icono que Dios nos da de Sí mismo. Marion lo presenta con la palabra dios cruzada por un signo en forma de cruz. Eso significar que la imagen que Dios ha querido dar de Sí mismo es un dios escondido en la cruz, y que es en la cruz donde lo encontramos. Para Marion no se trata del ídolo creado por el hombre, sino del icono que Dios nos ofrece, Jesucristo crucificado.

La opción de la fe cristiana vivida de una manera personal y auténtica lleva a aceptar la paradoja de que la vida que Dios nos da brota de Jesucristo crucificado. El Dios que nos hace vivir en Jesucristo no impone su poder, sino, al contrario, renuncia a él escondiéndose en la impotencia de la cruz. A partir de esta afirmación todo es posible, ya que aquella vida aparece como libertad. La vida dada al hombre es vida sin exclusiones ofrecida a todos los hombres y mujeres, de todas las condiciones. El pluralismo pasa a ser la traducción de la universalidad de aquella vida que no es negada a nadie. Que una multiplicidad de caminos se abra desde la cruz de Jesús implica también que los hombres llegan a Dios por una pluralidad de caminos. La vida del hombre permanece abierta. Podríamos terminar con la frase de Buber: 
Dios no dice: este camino lleva hacia mí y este otro no lleva, sino: Cualquier cosa que hagas puede ser un camino que lleve hacia mí, mientras que tú te comportes de tal manera que eso te lleve hacia mí. ${ }^{36}$

La exposición de la transcendencia como dimensión de la persona nos tiene que permitir también esbozar unas líneas educativas que la tengan en cuenta precisamente en la encrucijada de ideas y de caracteres que constituye la humanidad de nuestro mundo. No quiero esconder la dificultad que impone la realidad de un mundo secularizado que parece exigir silencio sobre la dimensión transcendente del hombre. Los creyentes del nuestro tiempo nos hemos impuesto un silencio pudoroso respecto de la manifestación pública de nuestras creencias, pero precisamente aquí es donde me permito ser crítico. Una cosa es la afirmación de la transcendencia, como dimensión humana, y otra es la respuesta concreta que cada quien da a la llamada que se le dirige desde su propia fe. De la misma manera que en este punto hay que ser respetuosos con las respuestas dadas por otros desde otras situaciones y compromisos diversos, hay que proponer con tenacidad la profundización de cada educando en la búsqueda espiritual de sí mismo. Teniendo presentes las dificultades que nuestra sociedad opone a la búsqueda del transcendente, que coinciden con las negaciones que se oponen al camino de una verdadera eclosión de la persona, creo que hace falta plantar cara. Si la falta de espíritu crítico es un obstáculo para hacerse preguntas sobre sí mismo, hay que fomentar el espíritu crítico. Si el mundo de ruido y activismo impide entrar en sí mismo y descubrir la propia interioridad, hay que practicar de vez en cuando el silencio y la meditación para acceder al interior de uno mismo. Si nuestra sociedad ofrece sólo facilidades y propone respuestas inmediatas a la caza de un bienestar fácil, hay que oponerle la pedagogía del no, de la dificultad, de la audacia, para ayudar a vencer los obstáculos y a otear hacia horizontes más dilatados. La propuesta de actividades de reflexión, de encuentro o de plegaria no se debe excluir, ya que es una oportunidad que muchos quizás agradecerán. Todos esos elementos hacen posible crear una zona de experiencia. No hemos dicho todavía que la propuesta sea específicamente religiosa y de connotación confesional, pero es el terreno en que ésta se podrá dar.

Un segundo grado de profundización en el transcendente puede ser la comunicación específicamente religiosa, que es de libre elección y se traduce en una pluralidad de respuestas. El pluralismo cultural y religioso de nuestra sociedad ha de permitir presentar diversas experiencias culturales del hecho religioso en general, como una propuesta verdaderamente humana y ofrecida a la experiencia. La posibi-

${ }^{36}$ BUBER, M. Le chemin de l'homme, op. cit., p. 20. 
lidad de comunicar con diversas concepciones de lo sagrado puede eliminar la impresión de un proselitismo directamente confesional. Dios puede ser dicho de diversas maneras y la dimensión religiosa puede abrirse a diferentes actitudes. Un verdadero universalismo tiene que conducir a un sentido amplio de la fraternidad universal a pesar de las diferencias. Sin embargo, tales viajes culturales no deben ni un relativismo ni un arenisco difuso por parte de quien cree, que tiene que testificar siempre su fe.

La dificultad mayor para el creyente es encontrar el lenguaje adecuado para hablar de Dios. Venimos de una tradición que ha vivido bajo muchas representaciones de un Dios impresentable, justiciero, vengativo, exigente, distante, dueño. Estas imágenes han deteriorado a menudo la propia fe, que tiene dificultades para transmitir con fidelidad el núcleo en que creemos. Con este bagaje no nos atrevimos a intervenir en la vida de los demás, por miedo de extraviar sus caminos, ya que pensamos que un día se extraviaron los nuestros. Todos estos prejuicios son nuestros, pero no lo son para los jóvenes de las nuevas generaciones que no vivieron aquellas confusiones. Tal vez lo único que experimentan son nuestros titubeos. Estoy convencido de que nuestra actitud creyente, si se manifiesta decidida y firme, no constituye ningún elemento negativo en la construcción de la persona del educando. Al contrario, puede ser un elemento constructivo de primer orden, por aquello del testimonio.

\section{Conclusión}

La filosofía personalista no es fundamentalmente religiosa ni cristiana, pero la confesión de fe le sienta bien. Por tanto, una escuela personalista que ha tomado sobre sí la connotación confesional no hace nada mal hecho si se manifiesta como tal y propone un estilo y unas maneras de hacer coherentes con aquella fe. Quien entre en ella sabe qué encontrarán allí y aceptan que aquellas ideas formuladas expresamente intervengan de una u otra manera en el modelo educativo. También es cierto que la escuela que se inspira en un pensamiento personalista lo hará con un respeto profundo por la persona del otro, separando bien lo que es necesario de lo que es de libre elección. Así, no es de extrañar que la información religiosa tenga un lugar en el proyecto educativo personalista, como un tema que interesa a todos, igual que la información artística, histórica o filosófica. Tampoco debería extrañar que a aquellos que se adhieren a la opción cristiana se les ofrezcan actividades formativas propias de su fe, como catequesis o la celebración de los sacramentos. Donde habría que encontrar el punto justo de una intervención 
confesional es en el aspecto de la evangelización, como llamada dirigida a todos a creer en Jesús, pero es difícil encontrar la manera de introducirla más allá de la iniciativa individual. Otra cosa son las campañas concretas de ayuda a los necesitados, a los refugiados o a los residentes en países del Tercer Mundo, que pueden revestir fórmulas humanitarias que interpelan prescindiendo de las adhesiones confesionales, pero que a menudo se vehiculan a través de instituciones católicas. Encontrar las fórmulas correctas resulta difícil, pero una vez sentado el principio de que no hay que eludir la propuesta del transcendente, cada situación señalará el momento y la forma oportuna de hacerla posible.

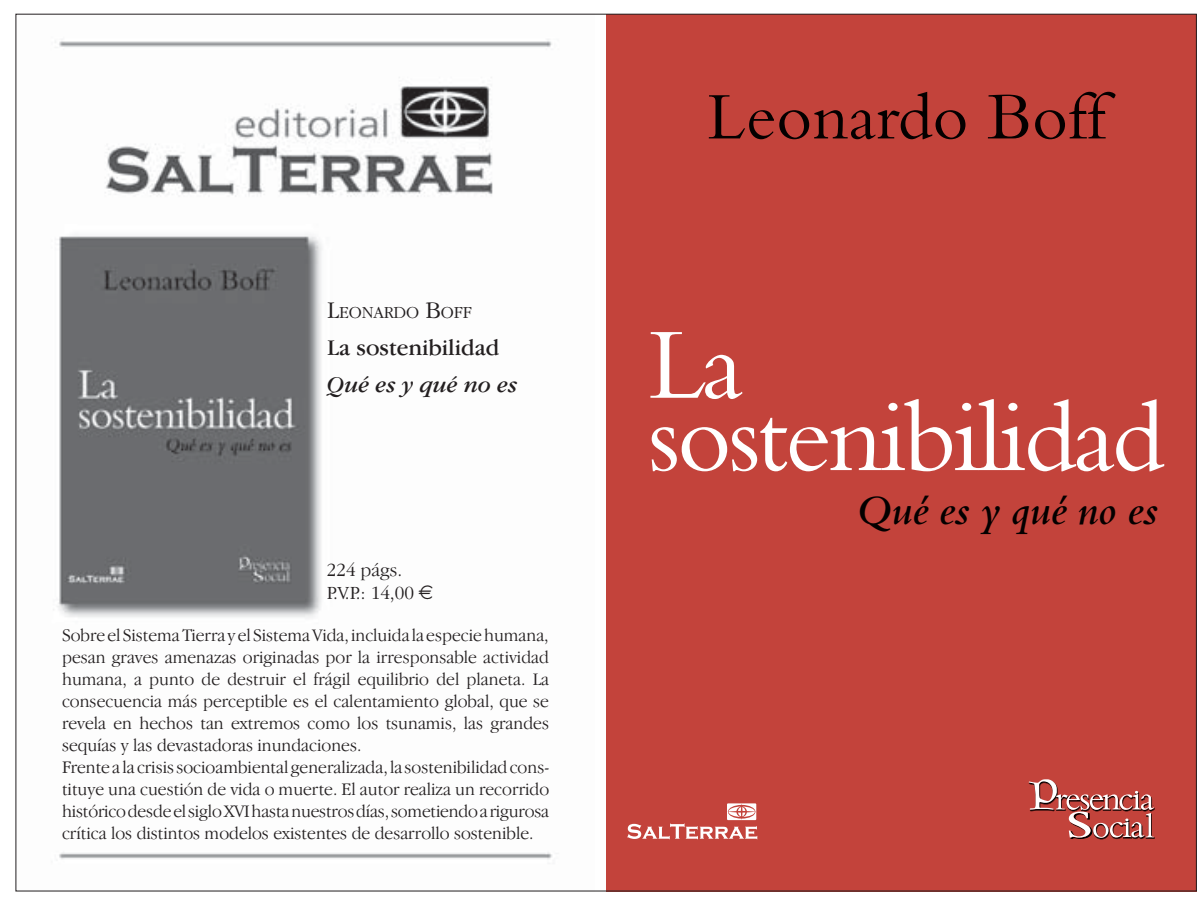

